\title{
Synthetic modelling of downhole resistivity data to improve interpretation of basin morphology from magnetotelluric inversion
}

Janelle M. Simpson ${ }^{1 *}$ and Graham Heinson ${ }^{2}$

\begin{abstract}
Prospective Proterozoic units in the southern Mount Isa Province are concealed by a poorly defined extent of younger basin cover, leading to poor exploration success. Collection of a magnetotelluric (MT) survey in the area containing 809 broadband MT (BBMT) and 855 audiomagnetotelluric (AMT) stations in 2014-2015, offers an opportunity to better model the depth to basement to enable effective exploration. MT inversion models are inherently nonunique, requiring independent geophysical and geological constraint to reduce model uncertainty. Where data are not available to constrain inversion, alternative approaches to dealing in inversion variability are required. This study uses synthetic modelling based on well data combined with two kinds of inversion to generate an interpretation and quantify associated uncertainty. Downhole resistivity logs were obtained from three petroleum wells adjacent to the study area, and 1D resistivity models were generated from the downhole data. A suite of 1D and 2D MT inversion algorithms were tested to determine their ability to resolve basin layering and the basement interface. All inversion algorithms reproduced basin layering, but the basement interface was poorly resolved. A combination of Occam2D and 1D rjMcMC inversions were used to produce interpretation of the base of the Eromanga Basin, an intra-Georgina Basin low-resistivity layer and depth to basement, all of which have associated error estimates. This work highlights the importance of understanding inversion variability during interpretation of geological features, particularly in the absence of constraining information. Distribution of uncertainty between the interpretation features is significantly non-uniform, necessitating careful consideration of inversion results. By quantifying uncertainty rather than ignoring it, we produce an interpretation commensurate with data limitations that still provides valuable new information about the geology of the southern Mount Isa Province.
\end{abstract}

Keywords: Depth to basement, Magnetotelluric inversion, Synthetic modelling, Uncertainty quantification, Mount Isa Province, Georgina Basin, Eromanga Basin

\section{Introduction}

The Mount Isa Province is a world-class mining province hosting significant volumes of economic $\mathrm{Pb}, \mathrm{Zn}, \mathrm{Ag}, \mathrm{Cu}$, $\mathrm{Au}, \mathrm{Mo}$ and other critical metals. In the southern part of the Province prospective Paleoproterozoic units of the Isa, Calvert and Leichhardt Superbasins are entirely

\footnotetext{
*Correspondence: janelle.simpson@dnrme.qld.gov.au

${ }^{1}$ Geological Survey of Queensland, Department of Natural Resources, Mines and Energy, Queensland Government, PO Box 15216, City East, QLD 4002, Australia

Full list of author information is available at the end of the article
}

concealed beneath the Georgina and Eromanga Basins (Fig. 1; Walter et al. 1995; Greene 2010; Cook et al. 2013; Kruse et al. 2013; Withnall et al. 2013).

Previous drilling results indicate that basement depths in the study area (Fig. 1) range from less than $100 \mathrm{~m}$ in the north, to over $1 \mathrm{~km}$ in the south-west. Exploration in covered terranes is challenging, but the expected basement depth range in the study area is not deep enough to preclude successful exploration outcomes. Despite this, there has been no significant mineral discoveries in the southern concealed part of the Province. 

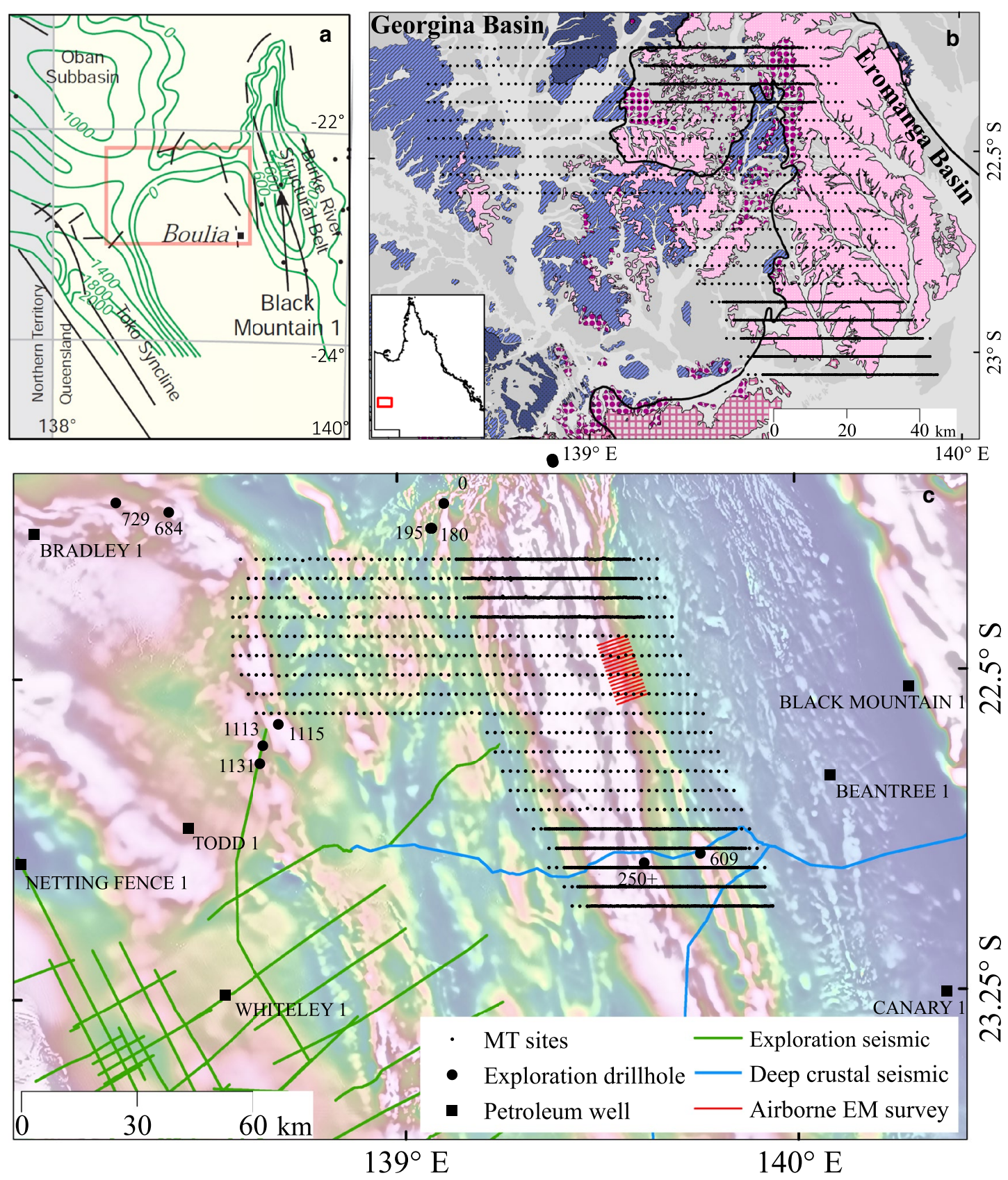

\section{Eromanga Basin}

Quaternary alluvium and

囲Wallumbilla Fm lacustrine deposits

Cenozoic sediments

Wilgunya Subgroup

Georgina Basin

MIVToko Group

VIIIAC Cockroach Group

Narpa Group

Fig. 1 Summary of mapped surface geology and available constraining information. a Location of the project area in red compared to Georgina Basin subbasins with project area indicated in red [modified after Withnall et al. (2013)]. b Mapped surface geology, thick black line denotes margin of the Eromanga Basin, points are the MT sites used for the study. c Composite first vertical derivative and total magnetic intensity map of the study area showing a north-south strike for the magnetic basement units. Available exploration data for study area also shown, exploration drill holes annotated with intersected basement depths or maximum hole depth where basement was not intersected (indicated by + after depth) 
Basin morphology, and more specifically depth to basement is a key consideration for mineral exploration. Many methodologies exist for deriving basement depth directly from potential field data, based primarily on automatic depth to magnetic source calculation (Werner 1953; Naudy 1971; Reid et al. 1990; Thurston and Smith 1997; Moreau et al. 1999). Inversion of potential field data can also be used to estimate the thickness of sedimentary cover (Barbosa et al. 1997; Gallardo-Delgado et al. 2003), however such studies typically do not resolve internal basin structures. While a simple interpretation of depth to basement may be sufficient for de-risking mineral exploration, additional information about the character of the cover sequences contributes to improving the geological understanding of an area.

There are two pre-existing depth to basement interpretations available in the project area (GSQ 2011; Frogtech Geoscience 2018). Both are primarily based on depth to magnetic source estimation and are broadly comparable, although the Frogtech Geoscience (2018) interpretation is newer and higher resolution. Comparison of the Frogtech Geoscience (2018) interpretation to known basement depths from drilling suggests that the basement interface is poorly resolved in this area by depth to magnetic source (Fig. 2). The Frogtech Geoscience (2018) study notes that there are extensive sequences of non-magnetic Paleoproterozoic packages in the Isa and Calvert Superbasins which are not detectable via their methodology, predominantly Euler depth to magnetic source estimation (Reid et al. 1990). The lack of magnetic basement units is the reason for the poor alignment between the current depth to basement models and basement intercepts from drilling. This is particularly

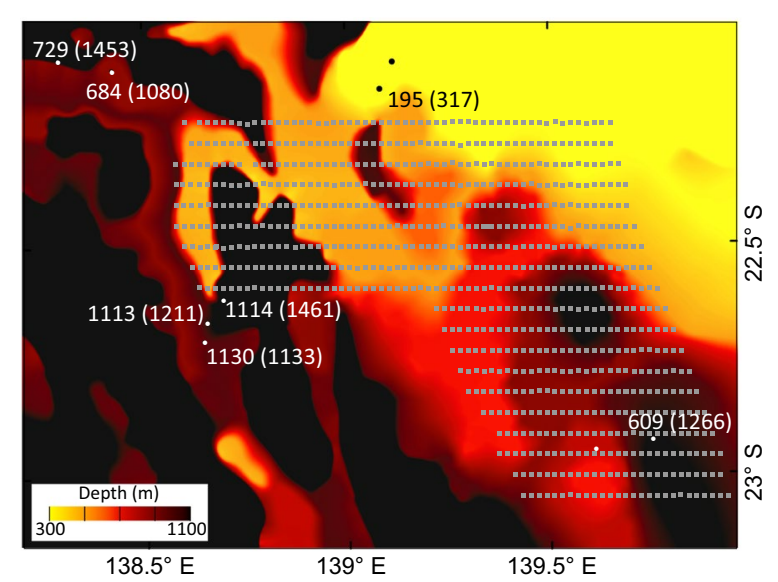

Fig. 2 Frogtech Geoscience (2018) depth to basement interpretation for the study area. Selected drillholes annotated with actual basement depth, predicted Frogtech basement depth in brackets problematic as one of the Superbasins not delineated by the current depth to basement is the Isa Superbasin which contains the Urquhart Shale, host to the worldclass Mount Isa $\mathrm{Zn}-\mathrm{Pb}-\mathrm{Ag}$ deposit (Withnall et al. 2013).

Electrical methods such as MT have the ability to resolve internal basin morphology and have been used to estimate basement depths (Zevallos et al. 2009; Cai and Zhdanov 2015; Carreira et al. 2018; Roach et al. 2018; Majcin et al. 2018). The distinction between the lower resistivity of the basin sediments and the higher resistivity of the underlying basement rocks is key to using electrical data for depth to basement studies (Cai and Zhdanov 2015). Decreased resistivity in basin units is primarily attributed to the presence of fluids in pore spaces or increased clay content (Evans 2012; Selway 2014). Magnetotelluric data are more typically used for crustal-scale tectonic studies, but depending on the range of frequencies collected and site spacing, can also provide information about shallow features. Near-surface resistivity plays a crucial role in depth of investigation, with low-resistivity surficial layers reducing the depth of investigation. Generally MT data with frequencies between 10 and $10,000 \mathrm{~Hz}$, and station spacing less than 1-2 $\mathrm{km}$ will provide valuable information about shallow $(<1 \mathrm{~km})$ resistivity structures.

A publicly available MT dataset was collected in the southern Mount Isa Province by the Geological Survey of Queensland in 2014 which contains over 1600 sites of either BBMT $\left(2.2 \times 10^{-4} \mathrm{~Hz}\right.$ to $\left.3 \times 10^{2} \mathrm{~Hz}\right)$ or AMT $\left(0.5 \mathrm{~Hz}\right.$ to $\left.10^{4} \mathrm{~Hz}\right)$ frequency ranges. The project area for this study does not contain sufficient independent data, coincident with the MT data to constrain the inversion or interpretation. Instead, we use synthetic modelling of downhole resistivity data adjacent to the area of interest to assist with selection of the most appropriate inversion algorithms and parameters. The synthetic modelling results are also used to guide interpretation. The study provides new information about the depth and character of the Eromanga and Georgina Basins in southwest Queensland. Areas of previously unknown Isa or Calvert Superbasin packages have also been identified.

\section{Geological background}

The Isa, Calvert and Leichhardt Superbasins were deposited between 1800 and $1575 \mathrm{Ma}$ and comprise multiply deformed metasedimentary and metaigneous rocks, which have been subsequently intruded by Mesoproterozoic granitoids (Gibson et al. 2016). For the purposes of this study basement is defined as pre-Neoproterozoic sequences attributed to these three Superbasins. The Georgina and Eromanga Basins overlie the basement in the study area. 
The Georgina Basin is a Neoproterozoic-to-early Palaeozoic epicratonic basin (Walter et al. 1995) present across part or all of the study area. There are three depocenters for the Georgina Basin adjacent to the study area: the Oban Subbasin, Toko Syncline and Bourke River Structural Belt. A thinned extent of the Georgina Basin is expected within the study area (Fig. 1a). The Toko, Cockroach and Narpa Groups are the outcropping Georgina Basin units (Figs. 1, 3). These units broadly date from the Cambrian to Ordovician and are carbonate dominated (Withnall et al. 2013). Drilling indicates that the older Morpunga and Shadow Groups are also present in the study area, though not exposed at the surface (Green et al. 1963; Kress 1989; Kress and Simeone 1993). Neoproterozoic rift packages underlying the Georgina Basin also occur in the broader region (Greene 2010), but have not been identified in the study area.

The Eromanga Basin is an Early Jurassic-to-Cretaceous cratonic sag basin (Cook et al. 2013) and overlays parts of the Georgina Basin in the east of the study area. The basin margin is contained within the study area, with sediments thickening to the east and south. The Eromanga Basin comprises the Wilgunya Subgroup and the Longsight Sandstone in the study area (Figs. 1, 3). These units are Upper Jurassic-to-Lower Cretaceous siliciclastic sediments and are dominantly mud-rich (Cook et al. 2013).

\section{Independent data}

Magnetotelluric data are inverted to produce resistivity depth models prior to interpretation. As with all geophysical inversion, MT inversion suffers from being inherently non-unique (Parker 1994). Incorporating independent information during inversion or interpretation can produce models consistent with a variety of datasets, thereby reducing the uncertainty in interpreting the inversion models (Le et al. 2016; Carreira et al. 2018; Roach et al. 2018). Some MT studies have successfully used seismic data as an additional constraint, either during inversion (Yan et al. 2017) or the interpretation process (Ogaya et al. 2016). Downhole resistivity log data have also been used either as a constraint during inversion (Yan 2016) or as a qualitative validation of inversion accuracy (Moorkamp et al. 2013). Another approach is the joint inversion of MT with potential field or seismic data to better constrain the outputs (Moorkamp et al. 2013; Le et al. 2016; Cai and Zhdanov 2017). These approaches all require coincident constraining information, limiting their application in data-poor areas. In quasi-1D environments where rock packages are relatively flat-lying, nearby information may be used to constrain inversion directly, however this method has the potential to introduce inappropriate bias into the inversion if the quasi-1D assumption is wrong.

A variety of geophysical and geological datasets are present in or near the study area to complement the MT dataset (Fig. 1c). Several exploration drillholes which intersect basement are present, however only one is coincident the MT data array. None of these exploration drillholes have associated resistivity logs, and the geological logging of basin sequences is generally poor. A small number of petroleum wells are available slightly further away from the main study area. These wells do have downhole resistivity logs and have detailed geological descriptions for the basin sequences.

An airborne EM survey (approximately 1200 line km) is present in the survey area, along with regional gravity coverage. The gravity data have a station spacing of $4 \mathrm{~km}$, making it too coarse to constrain the MT inversion. Finally, seismic data along 2D profiles are present near, but not within the study area. Data from a deep crustal seismic line are available, but the acquisition parameters and processing are poorly optimised to resolve shallow features.

\section{Methods \\ Field data analysis}

A collaboration between the Geological Survey of Queensland and Geoscience Australia produced BBMT and AMT data collected on a regional grid in the Boulia region of western Queensland (Fig. 1). A total of 809 BBMT stations were collected at $2 \mathrm{~km}$ station spacing $(\mathrm{E}-\mathrm{W})$ along $5-\mathrm{km}$ spaced profiles $(\mathrm{N}-\mathrm{S})$. The BBMT dataset was complemented by the collection of 855 AMT stations at $500 \mathrm{~m}$ spacing, co-located along nine of the BBMT profiles (Fig. 1). The higher resolution AMT collected information from 0.5 to $10^{4} \mathrm{~Hz}$ and the BBMT stations collected data from $2.2 \times 10^{-4}$ to $3 \times 10^{2} \mathrm{~Hz}$.

MT-py (Krieger and Peacock 2014) was used to determine dimensionality, geoelectric strike and the presence of galvanic distortion (Simpson and Bahr 2005). Phase tensor (Caldwell et al. 2004; Bibby et al. 2005) pseudosections and maps were produced to assess the character of the data and noise distribution. Geoelectric dimensionality was assessed through the phase tensor method (Caldwell et al. 2004; Bibby et al. 2005). The data were determined to be predominantly $1 \mathrm{D}$ at high frequencies $(>100 \mathrm{~Hz})$ and became 2D with decreasing frequency (Fig. 4). A small subset of stations in the west and north of the study area have 3D characteristics at frequencies lower than $10 \mathrm{~Hz}$.

The geoelectric strike for the 2D data was determined using MT-Py (Krieger and Peacock 2014). The average geoelectric strike for this dataset was $\mathrm{N} 85^{\circ} \mathrm{E}$ calculated based on the phase tensor (Caldwell et al. 2004; Bibby 


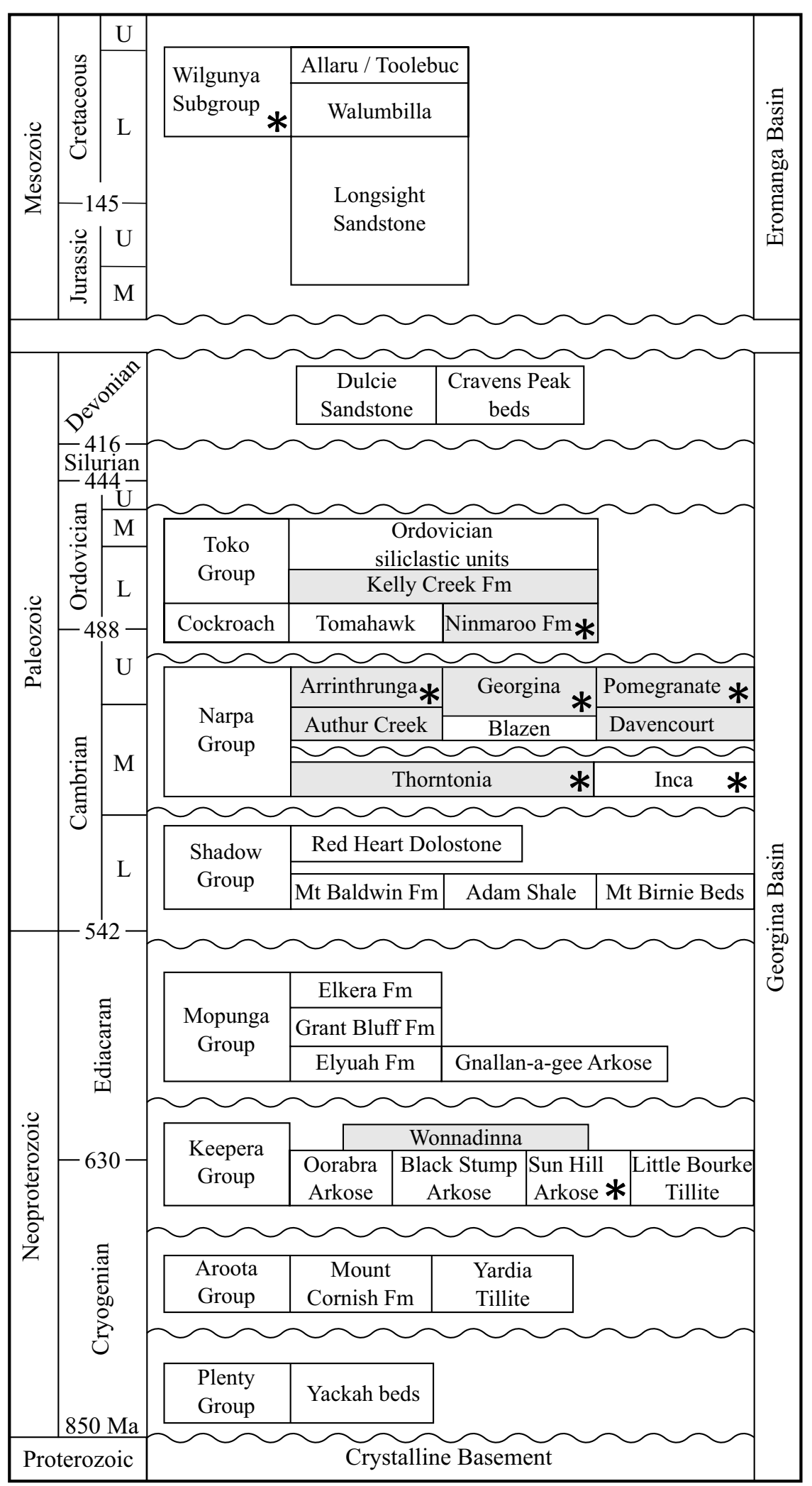

Fig. 3 Simplified stratigraphy for relevant units of the Georgina and Eromanga Basins. Modified after Greene (2010) with data from Ambrose et al. (2001), Draper (2007) and Kruse et al. (2013). Grey units are predominantly limestone, and white units are siliciclastic. Starred units intersected by boreholes Todd 1, Bradley 1 or Beantree 1 shown in Fig. 1 


\begin{tabular}{|c|}
\hline $00000,0000000000000000000000000000-000010-0000$ a \\
$000-00000000000001000-10000000000000000000000$ \\
$0-000000000000000000000000000000-0000000000$ \\
$1.25 \times 10^{-4}$ (s) \\
$0-00000000000-000000000-0000001-0000000000000$ \\
\hline $000000000010000000000-1000-000000000000000000$ b \\
\hline
\end{tabular}
00000000000,0000000001000000000010000000000000

$000000000100000000000000000000000000000-00010$ $1.25 \times 10^{-3}(\mathrm{~s})$

$01000000000000-00000000-10-000100000000000001$ 000000000000000000000000000000000000000000000 c 000000000000000000000000500000000000000000000

000000000000000000000000000000000000000000000 0.0125 (s)

0000000000000000000000000000000000000000000000

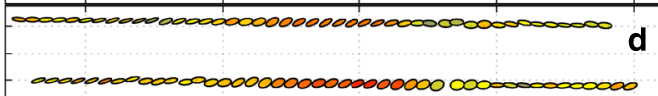

000000000000000000000000000000000000000000000

0.125 (s)

000000000000000000000000000000000000000000000

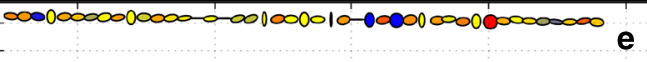

$00000000000000000-000000001000000000000000000$

$00000010000000000000000001-000010010-0000000$

1 (s)

0000000000000000000000000000000000000000000

$0=\Phi_{x y}=\Phi_{y x}=45^{\circ}$
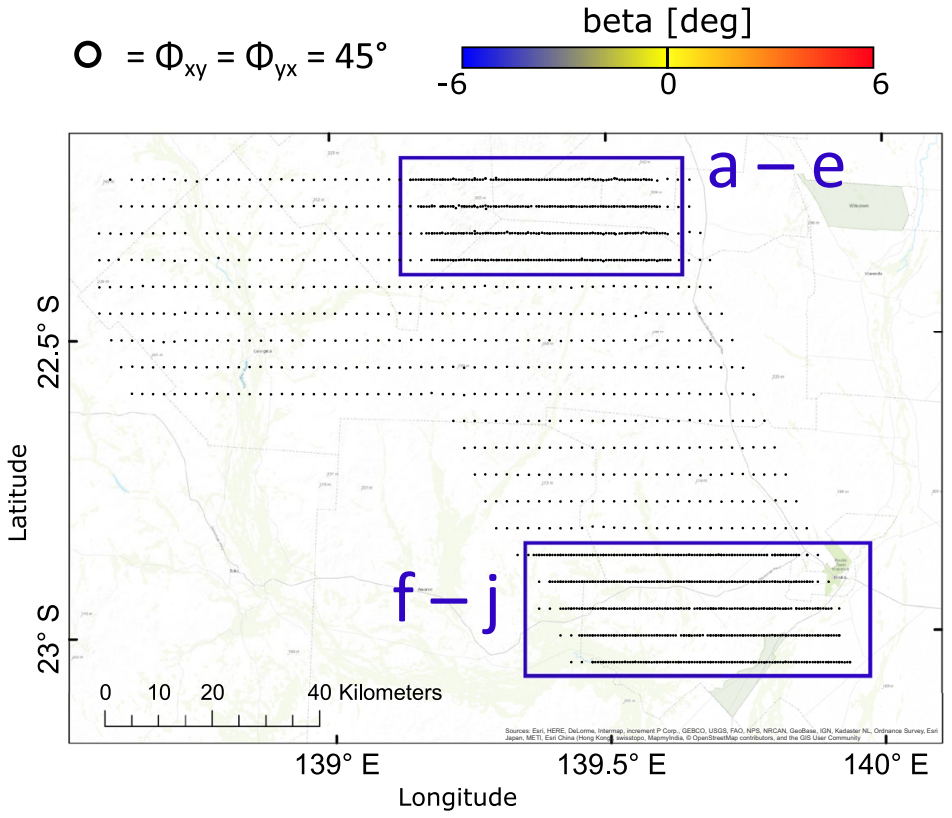
$1.25 \times 10^{-4}(\mathrm{~s})$

$1.25 \times 10^{-3}(\mathrm{~s})$ $0.0125(\mathrm{~s})$

1 (s)

)

000000000000000000000000000000000000000000000000

0000000000000000000000000000000000000000000000000

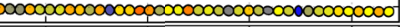

0000000000000000000000000000000000000000000000000 g

000000000000000000000000000000000000000000000000

000000000000000000000000000000000000000000000000000

00000000000000000000000000000000000000000000000000 h

0000000000000000000000000000000000000000000000000

000000000000000000000000000000000000000000000000

0000000000000000000000000000000000000000000000000000 00000000000000000000000000000000000000000000000000000

00000000000000000000000000000000000000000000000000000 i

00000000000000000000000000000000000000000000000000

0.125 (s)

00000000000000000000000000000000000000000000000000

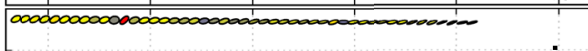

0000000000000000000000090909090000000000000000000 - j
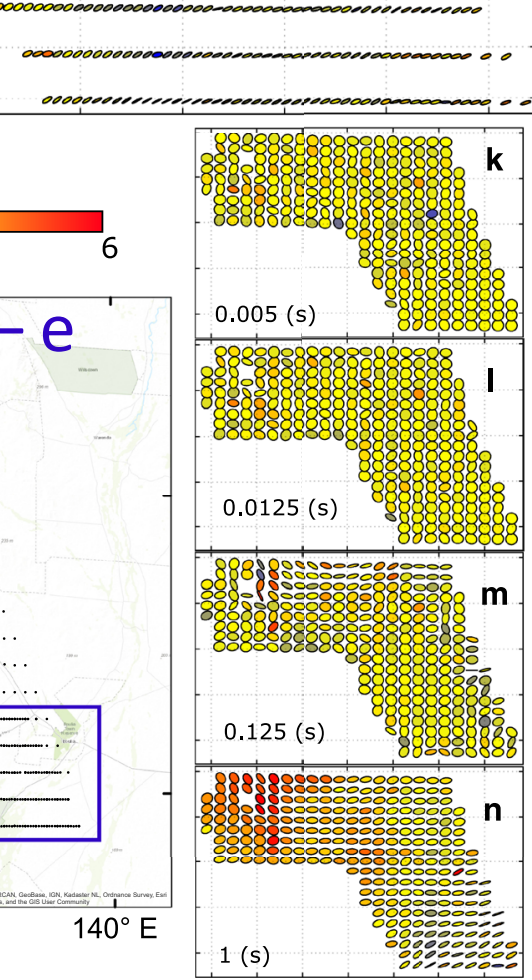

Fig. 4 Phase tensor plots coloured by skew for AMT and BBMT datasets (annotated with period). Data unaffected by noise are predominantly 1D at short periods, as indicated by yellow circular ellipses. Distorted ellipses with low skew values are indicative of 2D data, while ellipses with red or blue colouration indicate 3D subsurface structure. a-e north block AMT data, increased data noise responsible for scattering at $1 \mathrm{~s}, 1.25 \times 10^{-3} \mathrm{~s}$ and $1.25 \times 10^{-4} \mathrm{~s}$. $\mathbf{f}-\mathbf{j}$ southern block AMT data. $\mathbf{k}-\mathbf{n}$ data for BBMT sites, western sites are $3 \mathrm{D}$ at $1 \mathrm{~s}$. Displayed ellipses were generated using one-third of the total BBMT sites and half of all AMT sites for clarity 
et al. 2005) and impedance tensor invariant (Weaver et al. 2000; Weaver and Lilley 2004) methods. The strike analysis has a $90^{\circ}$ ambiguity (Thiel 2008), but the geological trends show that the strike is $\mathrm{N} 5^{\circ} \mathrm{W}$. Static shift was accounted for during inversion (e.g. Ogawa 2002).

The northern block of AMT stations was significantly affected by low signal-to-noise ratio in the deadband while the southern AMT block was relatively unaffected (Fig. 8). This effect is confined to frequencies between 3000 and $5000 \mathrm{~Hz}$ or below $1 \mathrm{~Hz}$ due to low signal due to daytime acquisition (Garcia and Jones 2008), and data were masked to minimise its effect during inversion.

\section{Synthetic modelling}

Three petroleum wells with downhole resistivity logs are available near the study area (Fig. 1c). These wells are not inside the study area and therefore cannot be used to directly constrain the inversion, as suggested in Yan (2016). Instead, they have been used to understand the expected resistivity of the basin sequences and basement. The airborne electromagnetic survey was used to supplement the petroleum wells to characterise the resistivity for the shallow Eromanga Basin units (Fig. 1c).

Downhole resistivity data were extracted from well completion reports; approximate depth of extracted data was $1400 \mathrm{~m}, 900 \mathrm{~m}$ and $650 \mathrm{~m}$ for Todd1, Bradley1 and Beantree1, respectively (Green et al. 1963; Kress 1989; Kress and Simeone 1993). The downhole resistivity data were averaged over areas of consistent resistivity response in $\log _{10}$ space and each model named after their respective source wells, Todd1, Bradley1 and Beantree1 (see Fig. 5 for comparison between downhole resistivity and averaged model). Synthetic MT data were generated for the three averaged borehole models using ModEM 3D (Egbert and Kelbert 2012; Kelbert et al. 2014). Synthetic data had a frequency range $10 \mathrm{~Hz}$ to $10^{4} \mathrm{~Hz}$, with five points per decade. This bandwidth was chosen as it represents the frequency range of $1 \mathrm{D} / 2 \mathrm{D}$ data in the field data. Synthetic data had 2.5\% Gaussian noise added, and were generated at three sites $500 \mathrm{~m}$ apart for each model. While the input model was 1D, generating data with noise added at three sites enabled testing of $2 \mathrm{D}$ inversion implementations. These data were used to produce inversions with a variety of inversion algorithms to assess which methods provided the best recovery of the original structure (Fig. 5).

\section{Synthetic 1D inversion}

Three 1D inversion algorithms were chosen for testing: Occam; SimPEG; and rj-McMC (Constable et al. 1987; Cockett et al. 2015; Brodie and Jiang 2018). These algorithms were chosen as they are all open source and represent a combination of deterministic and probabilistic inversion.

Occam inversion (Constable et al. 1987; deGroot-Hedlin and Constable 1990) is a deterministic method which runs as a two-stage process. Initially, the inversion minimises data misfit. When a specified misfit is achieved the inversion then reduces the model norm (a measure of roughness) while maintaining the misfit. The Occam approach produces the smoothest model possible for a given misfit.

Occam 1D inversions (Constable et al. 1987) were conducted with data frequencies higher than $10 \mathrm{~Hz}$. The models had a maximum depth of $7.5 \mathrm{~km}$ with a target depth of $2 \mathrm{~km}$. Two inversions were run for each model, one with the minimum number of layers (n) required for the inversion to achieve an RMS of 1 and converge appropriately $(n=8$ for Bradley1 and Beantree1; $n=9$ for Todd1). The second inversion used an arbitrarily large number of layers $(n=100)$ to investigate a smooth inversion result for the same data (Fig. 5).

SimPEG 1D (Cockett et al. 2015) is also a deterministic inversion approach with gradient-based optimisation. It differs from Occam in that the user can specify $\alpha_{\mathrm{s}}$ and $\alpha_{\mathrm{z}}$ parameters to control the smoothness and magnitude of the modelled resistivities, rather than creating a smooth model through minimisation of the first vertical derivative-the Occam approach.

The synthetic models were also inverted using MT1D from the SimPEG suite of algorithms (Cockett et al. 2015). SimPEG's inbuilt capability to generate data from synthetic models was used rather than the ModEM synthetic data. Data were generated with an error of $2.5 \%$, consistent with the ModEM synthetic data. Optimised values for key inversion parameters for each synthetic model were established through a series of inversion tests. The $\alpha s$, cooling factor, cooling rate, $\alpha_{\mathrm{z}}$ and $\mathrm{B}_{0}$ were all varied in an effort to produce an inversion model which closely resembled the synthetic model (Fig. 5). For all three models the $\alpha_{\mathrm{s}}=0.001$, cooling factor $=2$ and cooling rate $=1$. Beantree 1 and Bradley 1 had $\alpha_{\mathrm{z}}=1$, while Todd 1 had $\alpha_{\mathrm{z}}=2$. The $\mathrm{B}_{0}$ ratio was 6 for Bradley 1 and Todd1, and 8 for Beantree1.

The final 1D algorithm tested was rj-McMC. The rjMcMC MT1D algorithm uses trans-dimensional Markov chain Monte Carlo techniques to perform 1D magnetotelluric inversion via Bayesian inference (Brodie and Jiang, 2018). The trans-dimensional approach allows the number of layers to be an inversion parameter, rather than being fixed for an inversion. The inversion routine produces a probability distribution of resistivity vs. depth and automatically generates change point peaks for use in interpretation. 

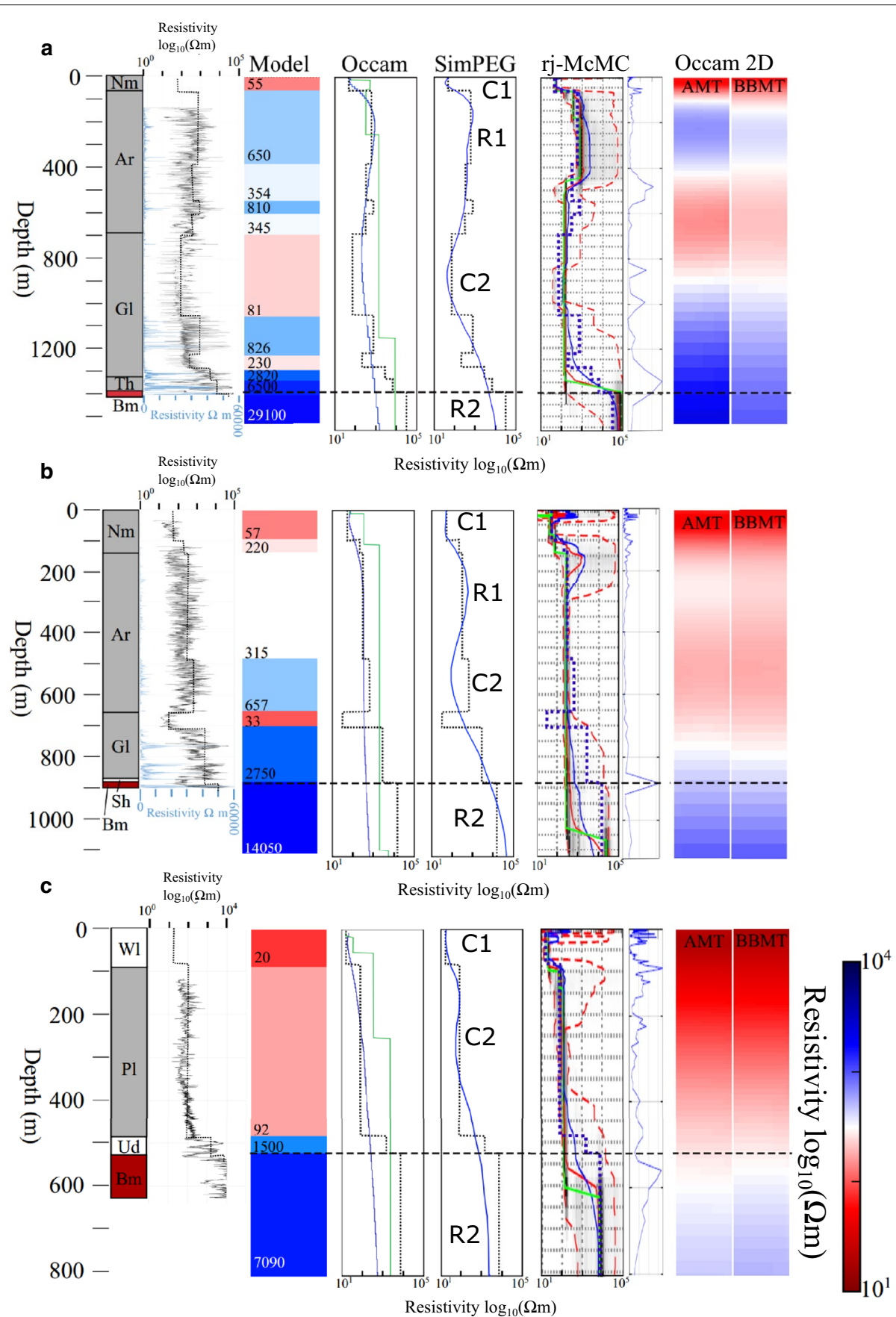

Fig. 5 Summary of synthetic modelling conducted using downhole resistivity from petroleum wells. a Todd 1 (Kress and Simeone 1993), b Bradley 1 (Kress 1989), and c Beantree 1 (Green et al. 1963). From left to right for: downhole logged geology, limestone units in grey, siliciclastic units in white and basement in red; measured downhole resistivity, black logarithmic scale, blue linear scale, dashed line represents the averaged resistivity used to create the 1D model; 1D synthetic model created from downhole resistivity data, annotated with resistivity $(\Omega m)$, basement interface indicated with black dashed line; results from Occam1D inversion, model in thick dashed line, minimum layer model green, $n=100$ model blue; 1D MT SimPEG inversion, model in dashed line, inverted response in blue, major resistivity packages annotated; rj-McMC MT inversion with automatically generated changepoint probability; Occam 2D inversion results for BBMT and AMT frequency ranges. Colour scale applies to all plots, including models. Gl Georgina Limestone, Bm basement, Ar Arrinthrunga Formation, Nm Nimaroo Formation, Sh Sun Hill Arkose, PI Pomegranate Limestone, Ud Undifferentiated, Ar Arrinthrunga Formation, WI Wilgunya Subgroup, Nm Nimaroo Formation, Th Thorntonia Limestone 
ModEM synthetic data were also used with the rjMcMC algorithm (Brodie and Jiang 2018). Inversions were parameterised to have a maximum number of layers of 20 and maximum layer depth of $2000 \mathrm{~m}$. Selection of these parameters was informed by the complexity of the available downhole resistivity data and maximum expected basement depths from drilling. The frequency range was limited to $10-10^{4} \mathrm{~Hz}$, and permissible resistivity values limited between $10^{-1}$ and $10^{5} \Omega \mathrm{m}$. Inversions were run for $10^{4}$ burn-in samples and $10^{5}$ total samples. Inversions were run on four chains and no resistivity gradient priors were used.

\section{Synthetic 2D inversion}

Two-dimensional testing was conducted as it was determined that $2 \mathrm{D}$ inversion would be required for some parts of the project area to adequately model the field data. Occam 2D was selected for testing 2D inversion of the synthetic models, primarily as it is open source. Occam 2D inversion (deGroot-Hedlin and Constable 1990) was conducted using the ModEM generated synthetic data, with all inversion files prepared using MT-py codes (Krieger and Peacock 2014). Inversion mesh was parameterised to $3 \mathrm{~km}$ depth, with a first layer thickness of $5 \mathrm{~m}$. All inversions used both the TE and TM components and were started from a $100 \Omega \mathrm{m}$ half space. A series of inversions were run for each synthetic dataset to test the effect of the number of layers on inversion products. The number of layers tested was $n=20,40$, 60, 80 and 100. Models achieved an RMS of 1 and ran to convergence. The preferred inversion parameters were selected based on the agreement between the synthetic and inversion models. The final inversions (Fig. 5) were run with $n=60$.

Field data across much of the project area have limited high-frequency data available, limited either due to acquisition parameters or deadband noise. The effect of input frequency range was tested for 2D Occam inversion algorithms. This testing was used to determine what difference the missing high-frequency data $(10,000-300 \mathrm{~Hz})$ would have during inversion of the BBMT sites. The synthetic data were subset to frequencies between $1 \mathrm{~Hz}$ and $300 \mathrm{~Hz}$ to represent BBMT data collected in the study area. These data were inverted using the same parameters as the AMT frequency inversions and outputs compared (Fig. 5).

\section{Field data inversion}

The AMT and BBMT data were truncated to frequencies above $10 \mathrm{~Hz}$ to remove 3D data, and inverted using rjMcMC and Occam 2D. These two codes were selected for inversion of the field data based on the outcomes of synthetic modelling. Additionally, the rj-McMC inversion algorithm is probabilistic offering an estimate of uncertainty (Brodie and Jiang, 2018). Occam2D was selected to ensure the $2 \mathrm{D}$ data in the project area were adequately modelled and provide results for interpretation with a high degree of lateral continuity.

The rj-McMC inversions were parameterised to have four chains, a maximum number of layers of 20 and maximum layer depth of $2000 \mathrm{~m}$. Permissible resistivity values limited between $10^{-1}$ and $10^{5} \Omega \mathrm{m}$ and inversions were run for $10^{4}$ burn-in samples and $10^{5}$ total samples. All available MT sites were inverted with rj-McMC. BBMT sites were run with an input frequency range of $10-3 \times 10^{2} \mathrm{~Hz}$. For AMT sites, noise affected sites were inverted with a reduced frequency range (RF) of $10-10^{3} \mathrm{~Hz}$, while sites unaffected by deadband noise had the full frequency $(\mathrm{FF})$ inverted $\left(10-10^{4} \mathrm{~Hz}\right)$.

Occam 2D inversion files were created with MTpy with mesh parameterised to $3 \mathrm{~km}$ depth and a first layer thickness of $5 \mathrm{~m}$. All inversions used both the TE and TM components and were rotated to the strike of $\mathrm{N} 5^{\circ} \mathrm{W}$. Inversions were started from a $100 \Omega \mathrm{m}$ half space and parameterised to invert for static shift. Inversions were run with $n=60$, rho error floor $=5 \%$ and phase error floor $=0.2^{\circ}$. Occam inversions ran to an average RMS of 1.2 .

\section{Results}

\section{Synthetic modelling results}

The inversion algorithms tested recovered varying levels of the original structure (Fig. 5). No models were run with a priori geological information as this information is not reliably available for inversion of field data. While no algorithm was able to recover the full original structure from a half space starting model, a reasonable approximation of the synthetic model was generated by all test inversions (Fig. 5). Inversion models for Todd1 and Bradley1 contain a similar four-layer resistivity structure, while inversion of the Beantree1 synthetic data produces a three-layer inversion model (Fig. 5). The features have been labelled $\mathrm{C} 1$ and $\mathrm{C} 2$ for the low-resistivity layers and R1 and R2 for the high-resistivity layers to enable easy discussion. These labels are also employed for the field data inversions.

The minimum layer Occam 1D models do not reproduce features from the synthetic models (Fig. 5). The smooth ( $n=100$ layer) Occam inversion models are similar to the synthetic models for the shallow section, however the basement resistivity is poorly reproduced by these inversions (Fig. 5).

Inversion of data from the Todd 1 and Beantree 1 models using the SimPEG 1DMT algorithm produced models which closely resemble the synthetic models (Fig. 5a, c). Inversion results of the Bradley1 synthetic data using 
the SimPEG algorithm are broadly similar to the original synthetic modelling layers (Fig. 5b), however the narrow low-resistivity unit at approximately $600 \mathrm{~m}$ is poorly resolved.

The rj-McMC inversion results also generally reproduced the synthetic model features (Fig. 5). The true model is contained within the p10 to p90 bounds and typically resembles the mode model. The low-resistivity feature at approximately $600 \mathrm{~m}$ depth in the Bradley1 model is the only part of any model which does not plot within the p10 to p90 bounds (Fig. 5b). This feature is also not resolved by the SimPEG modelling and Occam results, suggesting it is not resolvable from the data. The rj-McMC inversion algorithm automatically generates change point peaks for use in interpretation; these peaks provide insight into where the layer interfaces are most likely to occur (Brodie and Jiang, 2018). The basement interface all three models has a change point peak in close proximity and is associated with a broad region, defined by $\mathrm{p} 10$ to $\mathrm{p} 90$ bounds, which represents a step change in the resistivity (Fig. 5).

Occam 2D inversions for the Beantree1 dataset produced a model which resembles the synthetic model (Fig. 5c). 2D Occam inversion results from Todd1 and Bradley1 are broadly similar to the synthetic model (Fig. 5a, b), however low-resistivity units occur at shallower depths, and the basement interface is not recognisable.

A comparison between inversions of BBMT and AMT frequency ranges was conducted using the Occam 2D algorithm. Inversion of synthetic data with only BBMT frequency ranges produced similar results to the AMT frequency ranges for all three synthetic models however the more limited high-frequency component for BBMT data, reduces the ability of inversions using the BBMT data to resolve shallow features sharply (Fig. 5). Despite this limitation inversion of the BBMT data reproduced shallow basin layering from synthetic data. The BBMT inversion tests generally had more smooth results compared to the AMT inversions.

The nature of probabilistic inversion allows additional insight to be gained through detailed inspection of the rjMcMC results. Of particular interest is the degree of variably associated with the inversion features. The $\mathrm{C} 1$ and $\mathrm{C} 2$ inversion features typically have a small spread in p10 and $\mathrm{p} 90$ bounds, implying they are well constrained. The top $100 \mathrm{~m}$ of $\mathrm{C} 1$ for Beantree1 and Bradley1 does have increased variability as indicated by the wider $\mathrm{p} 10-\mathrm{p} 90$ bounds. $\mathrm{R} 1$ is also variable but the average models generally produce the original resistivity structure. The ability of rj-McMC inversion to discern R1 likely comes from the fact that there is sufficient information in the data to resolve both the conductivity and conductance of the overlying conductive layer permitting a good estimate of the thickness of R1.

The large spread in p10 to p 90 bounds of results around the basement interface (contact between R2 and C2 for all models) for rj-McMC inversions suggest that the interface is not well resolved. Despite this, the changepoint peak predicts basement at approximately the correct depth in the tested models. It is likely that the changepoint peaks occur at around the correct depth because the data can resolve the averaged conductivity for the lower conductive and moderately resistive layers as well as the integrated conductance of the layers providing information on the thickness. Alternatively it is possible that the infinite thickness of the basement unit used to generate synthetic data, and absence of any structure within the synthetic basement, may spuriously increase the resolvability of basement in the testing.

A combination of noise levels and difficulties resolving thin layers at depth are primarily responsible for poor recovery of some model features. Other contributing factors to the inability to recover the full $1 \mathrm{D}$ model layering from the synthetic data are the diffusive physics of the MT problem and the regularisation used to stabilise the inversions. The inability to resolve the basement contact may be entirely due to the known difficulty in delineating conductor bottoms (Bedrosian 2007).

\section{Field data results}

Typical results for the rj-McMC and Occam 2D inversions, including data fits are presented in Figs. 6 and 7, respectively. Results for all Occam $2 \mathrm{D}$ inversion profiles are displayed in Fig. 8, and results from all rj-McMC inversions are available in Additional files 1 and 2.

The rj-McMC inversions commonly displayed structures similar to those in Fig. 6a, with a low-resistivity top layer $(\mathrm{C} 1)$, a moderate-resistivity layer with high uncertainty (R1), a low/moderate-resistivity layer with low uncertainty $(\mathrm{C} 2)$, and a high-resistivity basement layer (R2). Some inversions were missing the $\mathrm{C} 1$ features, consistent with the uneven distribution of the Eromanga Basin sediments across the study area. The R1 layer is missing from some of the 1D inversions (see Fig. 6b), similar to the results from synthetic modelling of Beantree1 data.

The same four-layer resistivity structure seen in the 1D inversions is evident in both the AMT and BBMT 2D Occam inversion results (Figs. 7, 8) for the majority of the study area. Inversion results for the BBMT data typically have higher roughness and poorer lateral continuity of structures than the AMT inversions, due primarily to increased station spacing. This difference aside, similar features are evident in the AMT and BBMT data (Figs. 7, 8). A small area in the east 
a

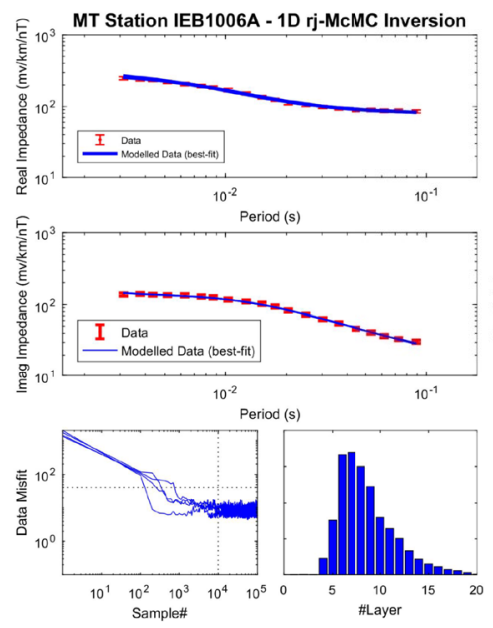

b
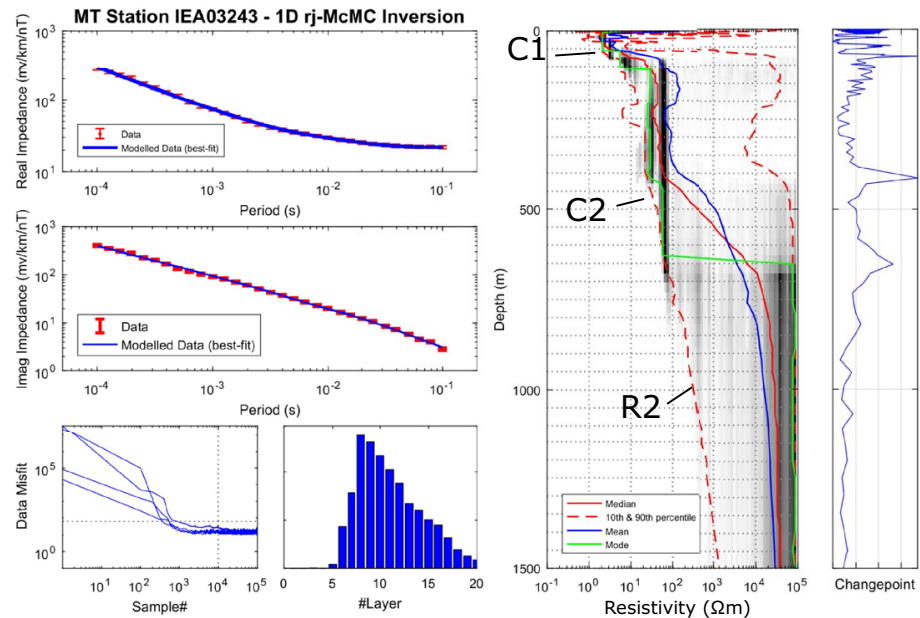

c
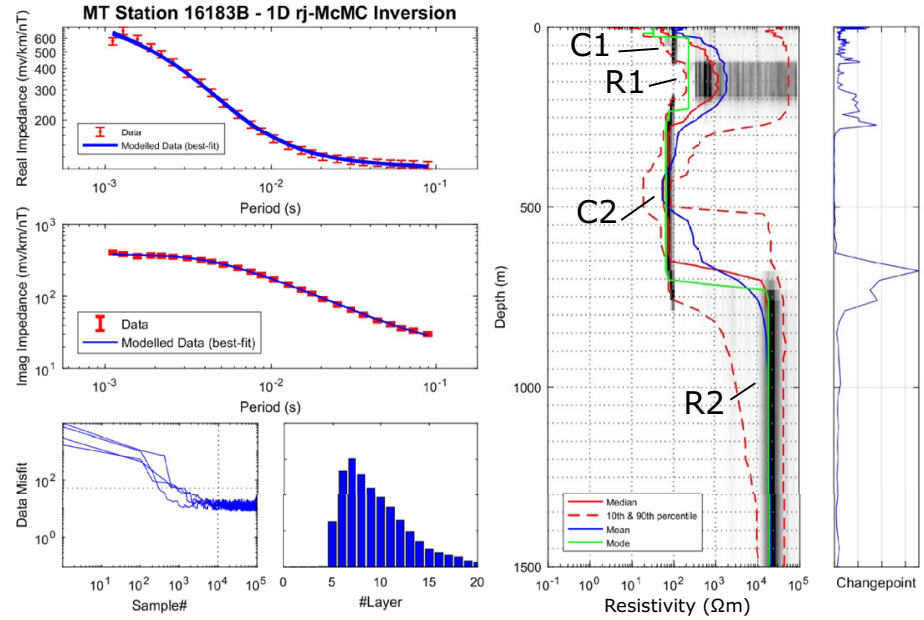

Fig. 6 Typical rj-MCMC 1D MT inversion results. a A BBMT site with interpretation picks indicated in cyan, $\mathbf{b}$ a full frequency AMT site and $\mathbf{c}$ reduced frequency AMT site. The data fit, misfit convergence, predicted number of layers and change point prediction curve for each site are displayed alongside the inversion model. The black-white colouration on the 1D model indicates model probability, with black areas indicating high probability structure. Inversion result plots for all MT sites can be found in Additional file 2 

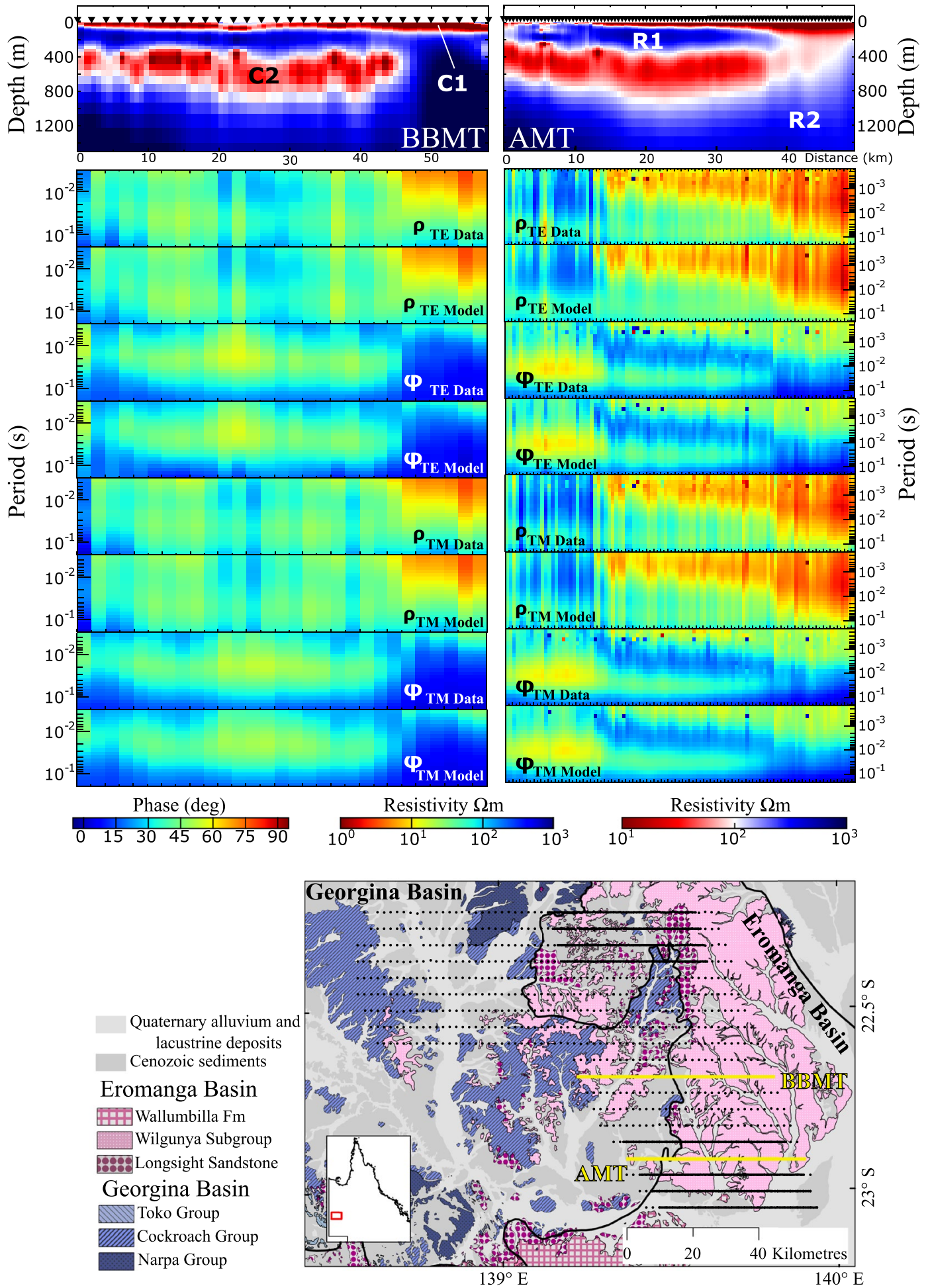

Fig. 7 Typical Occam 2D inversion results and data fit for BBMT (left) and AMT (right). Apparent resistivity $(\rho)$ and phase $(\varphi)$ pseudosections for the observed data compared to the calculated response (model) are displayed below the inversion section (top). Transverse electric (TE) and transverse magnetic (TM) modes both displayed. R1, R2, C1 and C2 features referred to in text are indicated. Location of two inversions indicated in yellow in bottom panel 


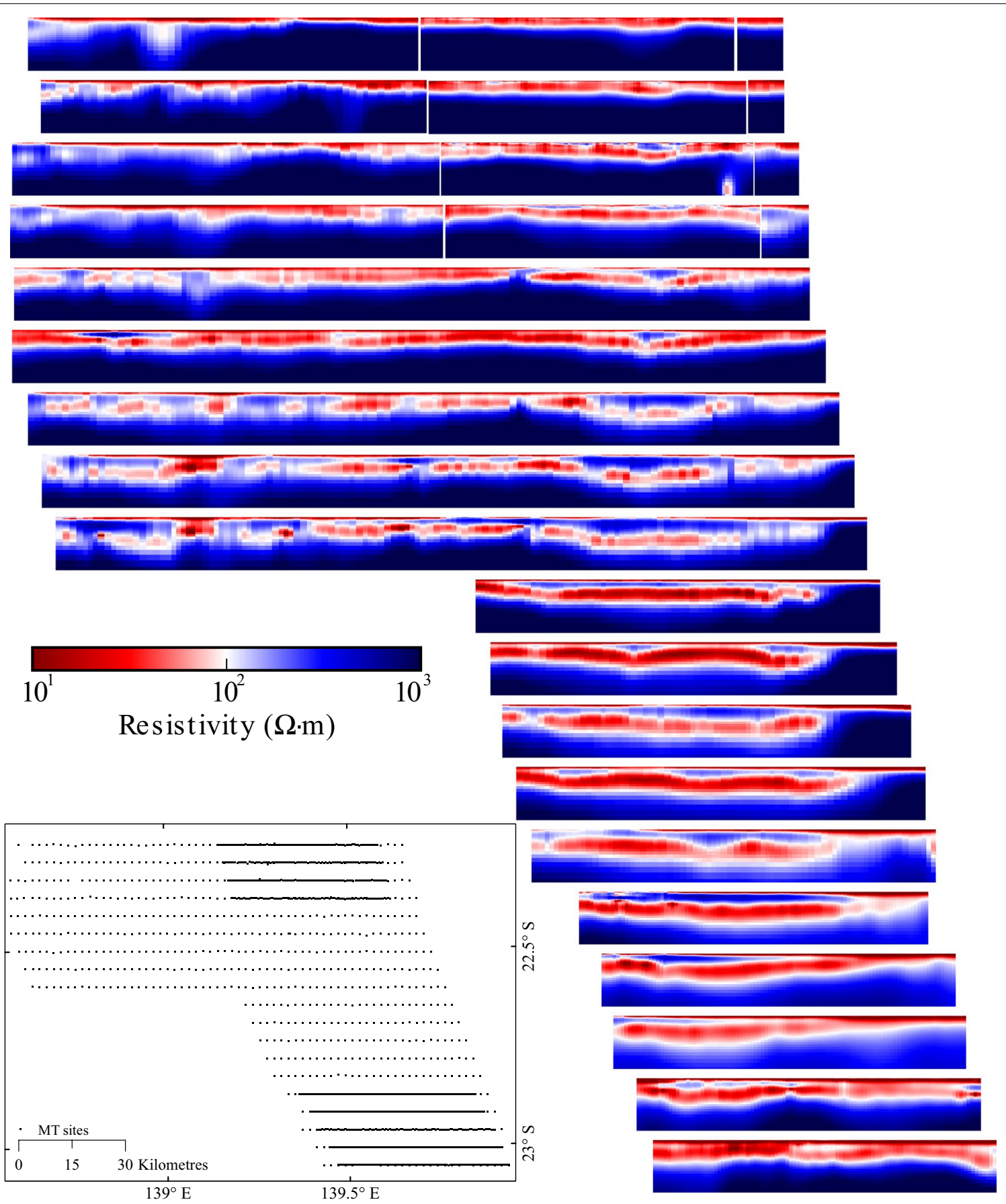

Fig. 8 Occam 2D inversion results for all profiles in study area. Where BBMT and AMT data are both present, only AMT inversion results are displayed. Location of all stations used for modelling shown in inset. Sections have a depth extent of $1500 \mathrm{~m}$

of the study area displays a two-layer resistivity signature (Fig. 8). This area corresponds to a thickening of Eromanga Basin sediments (C1), and it is not obvious whether the moderately conductive $\mathrm{C} 2$ feature is absent or being shielded by the overlying sediments. The $\mathrm{C} 2$ feature is distinctly imaged along the eastern end of southern 2 profiles which also have a thick extent for $\mathrm{C} 1$, suggesting the absence of $\mathrm{C} 2$ further north (also beneath thick Eromanga basin seds) may be real. 


\section{Interpretation workflow and criteria}

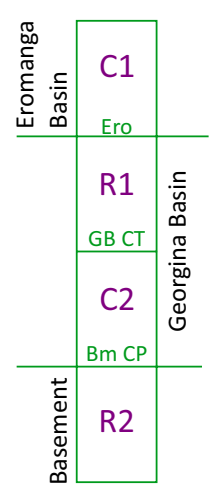

Fig. 9 Schematic summary of interpretation. Labelled features from $2 \mathrm{D}$ inversion are indicated in purple and picked interfaces based on 1D inversions are indicated in green. Macroscale geological subdivisions are indicated in black
A schematic representation of how the labelled resistivity features from the $2 \mathrm{D}$ inversion, related to the picked interfaces from 1D inversions and the macroscale geology is found in Fig. 9. The mean, mode, median, p10 and p90 curves from each rj-McMC inversion were imported into Geolog ${ }^{\circledR}$ alongside the change point curves for interpretation. Some of the 1D inversion results were not used due to poor data fit (as indicated in Additional file 1). Five interpretation 'picks' were generated in $\mathrm{Geolog}^{\circledR}$ based on the following criteria for the 1D inversions (Fig. 9; see also Fig. 10a for these picks applied to field data inversions):

1. Ero (base Eromanga Basin). Identifiable as the first significant increase in the mean/mode/median resistivity. Where possible, the Ero pick is interpreted using the change point peak. Resistivity of the first layer typically between 1 and $10 \Omega \mathrm{m}$, where the surface resistivity is greater than $10 \Omega \mathrm{m}$ and there is no

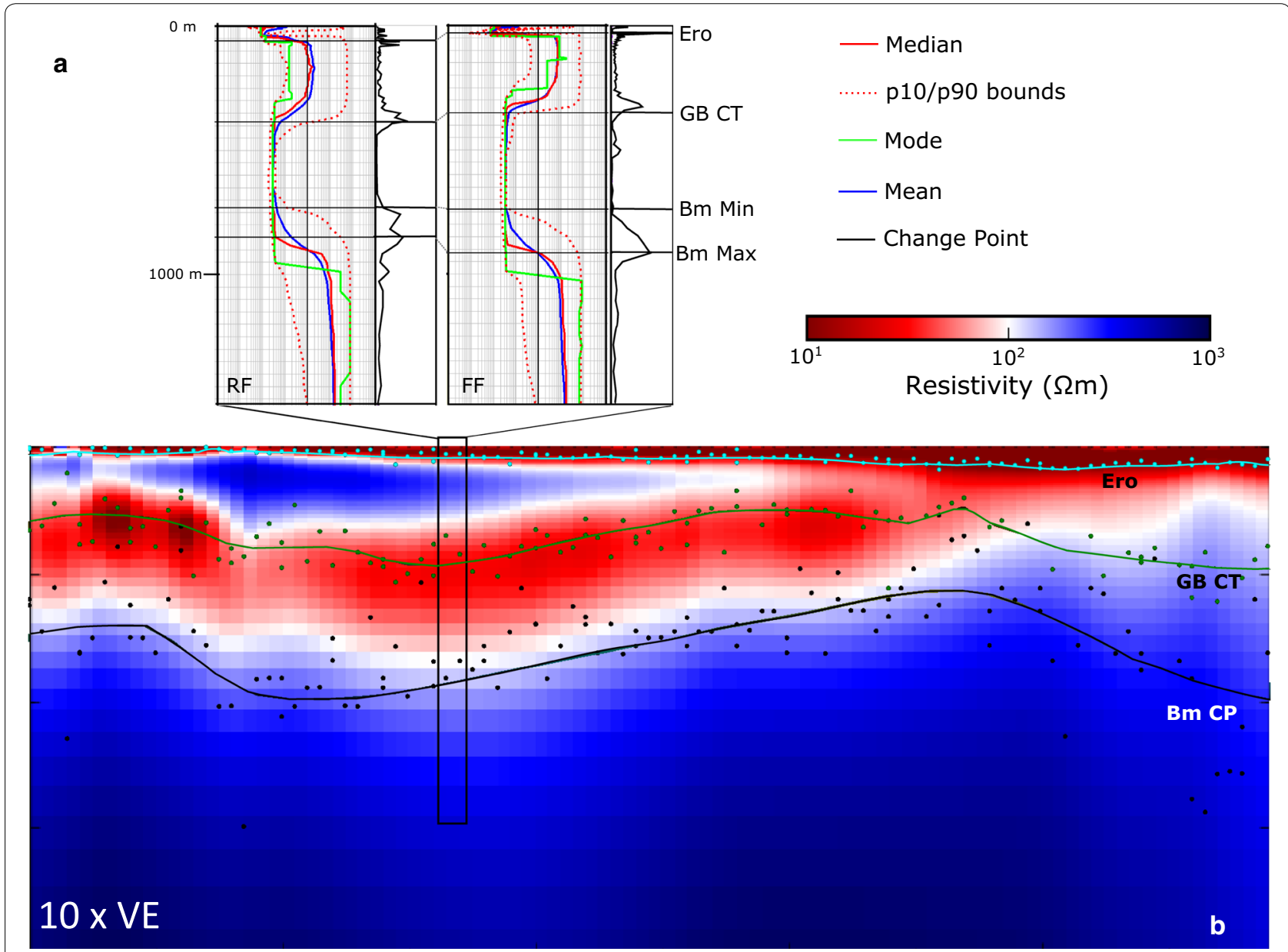

Fig. 10 Integrated 1D and 2D inversion interpretation summary. a Two rj-McMC inversion results as displayed in Geolog ${ }^{\circledR}$ with associated picks. b Picks from $1 \mathrm{D}$ inversions shown as points for Bm CP, Ero and GB CT layers with associated interpretation surfaces against the Occam 2D inversion result (coloured section) 
significant step in resistivity no Ero unit is picked. Final Ero picks refined based on mapped surface geology (Fig. 1a).

2. GB CT (Georgina Basin conductor top). Top of the section where the $\mathrm{p} 10-\mathrm{p} 90$ bounds are very narrow ( $<1$ order of magnitude).

3. Bm Min (basement minimum). Defined as the depth at which the p90 curve diverges from the mean, mode and medina curves below the GB CT pick.

4. Bm Max (basement maximum). The depth at which the p10 curve is greater than $1000 \Omega \mathrm{m}$.

5. Bm CP (basement change point). Defined at the highest probability change point contained between the Bm Min and Bm Max picks.

The results of $1 \mathrm{D}$ interpretation were then integrated with the 2D inversion results (Fig. 10) to produce the final interpretation (Fig. 11). GoCAD ${ }^{\circledR}$ was used to compare the $1 \mathrm{D}$ and $2 \mathrm{D}$ results, and create the final interpretation surfaces (Fig. 11). The 1D inversion picks displayed a large amount of scatter but by combining them with the $2 \mathrm{D}$ inversions is was possible to generate a cohesive interpretation (Fig. 11).

\section{Interpretation and estimation of uncertainty}

Three surfaces make up the final interpretation derived from integration of the 1D and 2D inversion results: base of Eromanga; top of Georgina Basin conductor; and basement (Fig. 11). The final extents of the base of Eromanga Basin interpretation (Fig. 11a) were constrained by the limits of outcropping Eromanga Basin sediments (Fig. 1). The interpretation of the depth to the top of the Georgina Basin conductor (C2) covers the entire area but there are two parts of the interpretation, indicated as hatched areas in Fig. 11c where it is uncertain whether that unit is present. The third interpretation surface is the base Georgina/basement interface (Fig. 11e).

Each interpreted interface has an associated uncertainty due to the scattering of 1D interpretation picks as shown in Fig. 10b. Some of the scatter in 1D inversion results is due to the presence of static shift at some sites, identified during data analysis. The presence of multi-dimensionality (i.e. 2D data) identified during data analysis also contributes to differences between the 2-D and 1-D inversion results and to some of the local variation in interface depth. Because of these factors, the error estimation based on the 1D inversion results may be higher than necessary. The difference between the final interpretation surface (e.g. Base Eromanga) and the 1D inversion pick at each site was calculated and is displayed in Fig. 11b, d, f. Figure 11g has a corresponding histogram plot for the uncertainty for each layer. The Base Eromanga and top Georgina conductor layers have an approximately normal distribution, indicating that the final interpretations surfaces are a fair representation of the 1D inversion results. The error for each surface is randomly distributed across the project area, indicating there are no spatial biases in the interpreted surfaces. The histogram for the base Georgina surface is slightly right skewed indicating that the final interpretation surface is shallower on average than the 1D inversions suggest. Based on the histograms an error of $\pm 20 \mathrm{~m}$ is assigned to the base Eromanga surface, $\pm 75 \mathrm{~m}$ to the top Georgina conductor and $\pm 200 \mathrm{~m}$ to the basement surface.

Due to the poorly constrained nature of the basement interface an additional estimate of uncertainty was calculated based on comparison between the Bm Min and Bm Max picks from 1D inversion, and the final base Georgina (basement) surface interpretation (Fig. 12). Synthetic testing suggests that the true basement interface will lie between the Bm Min and Bm Max, so the difference between these values and the base Georgina (basement) surface should provide a better estimate of the uncertainty than the scatter in 1D inversion results (Fig. 11f). The median difference between the Bm Min pick and the interpretation surface is $200 \mathrm{~m}$, while the median difference for the Bm Max pick is $446 \mathrm{~m}$. The percentage difference between the $\mathrm{Bm}$ Min/Bm Max and the base Georgina surface was also calculated (Fig. 12d). The uncertainty analysis suggests that the true basement surface may lie between 30\% shallower and $60 \%$ deeper than the final interpretation. Comparison to available drilling suggests these error margins are appropriate to encapsulate the true basement depth (Fig. 13).

\section{Discussion}

The presented methodology uses synthetic modelling based on downhole resistivity data to select inversion parameters and guide interpretation. Results from two styles of inversion are integrated with the well data to generate an interpretation with uncertainty estimates. The resulting interpretation provides an updated depth to basement surface for the study area, with definition of additional intra-basin layers unavailable in previous interpretations. Importantly, all interpretation surfaces have independent error estimates, ensuring that results are used in accordance with their reliability.

The 1D and 2D inversions generally produced comparable results. A notable exception to this generalisation is the disparity between $1 \mathrm{D}$ and $2 \mathrm{D}$ inversion in the east and north (see Fig. 10b; hatched areas on Fig. 11c). These areas correspond to increased skew values and ellipticity (Fig. $4 \mathrm{~m}$ ), suggesting they have a $2 \mathrm{D}$ electrical character. Consequently, the difference between the $1 \mathrm{D}$ and $2 \mathrm{D}$ inversions may be entirely due to the $1 \mathrm{D}$ inversion being 

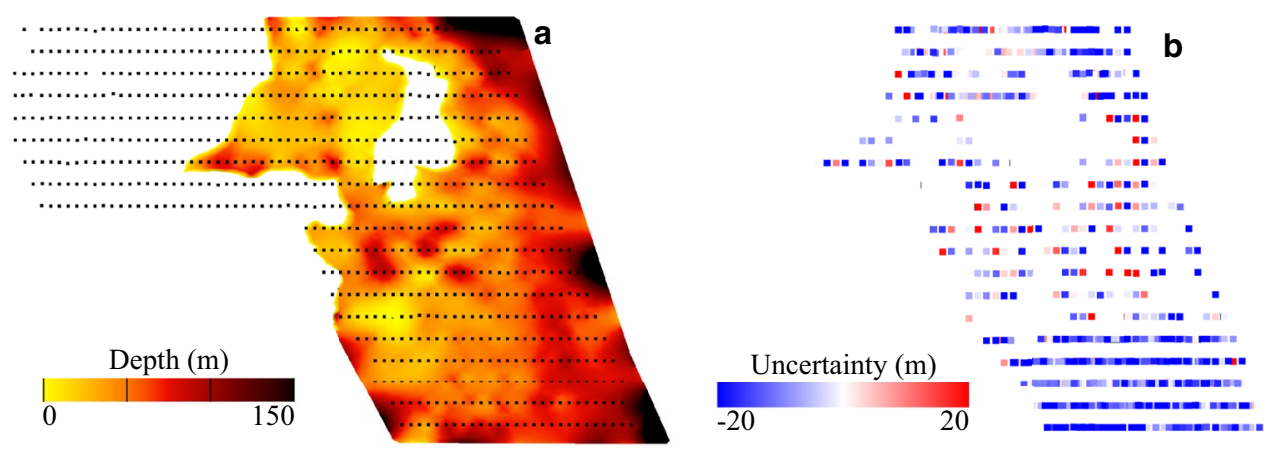

Base Eromanga
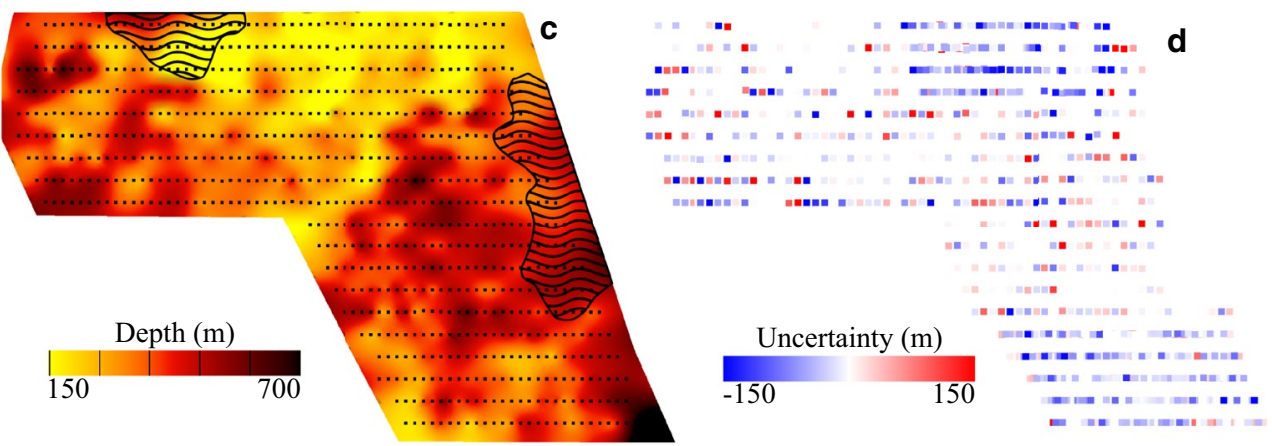

Top Georgina conductor

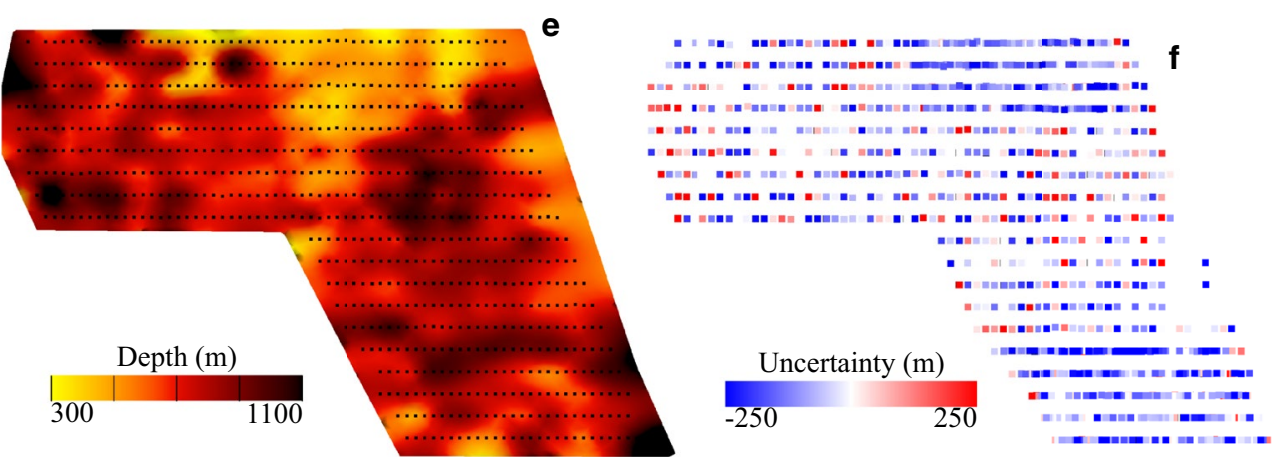

Base Georgina

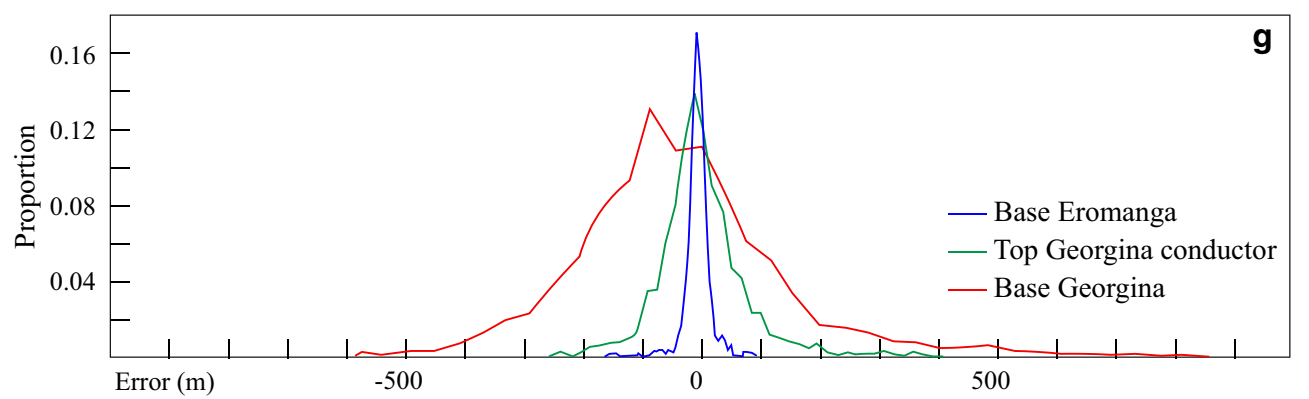

Fig. 11 Interpreted geological layers and associated uncertainty. a Interpreted base of Eromanga Basin, extents limited to location of Eromanga Basin sediments (Fig. 1b). b Uncertainty of base of Eromanga at each MT site, where a negative value indicates the final interpretation surface is shallower than the 1D inversion result, and a positive value indicates the interpretation is deeper than the 1D inversion result at that site. $\mathbf{c}$ Interpreted top of Georgina conductor (C2), black hatched areas indicate areas where the unit may be missing. $\mathbf{d}$ Uncertainty of the top of Georgina conductor layer based on difference between interpretation surface and 1D inversion pick. e Interpreted base Georgina (basement). f Uncertainty of the base Georgina interface based on difference between interpretation surface and 1D inversion pick. $\mathbf{g}$ Histogram distribution of errors for each interpretation layer 


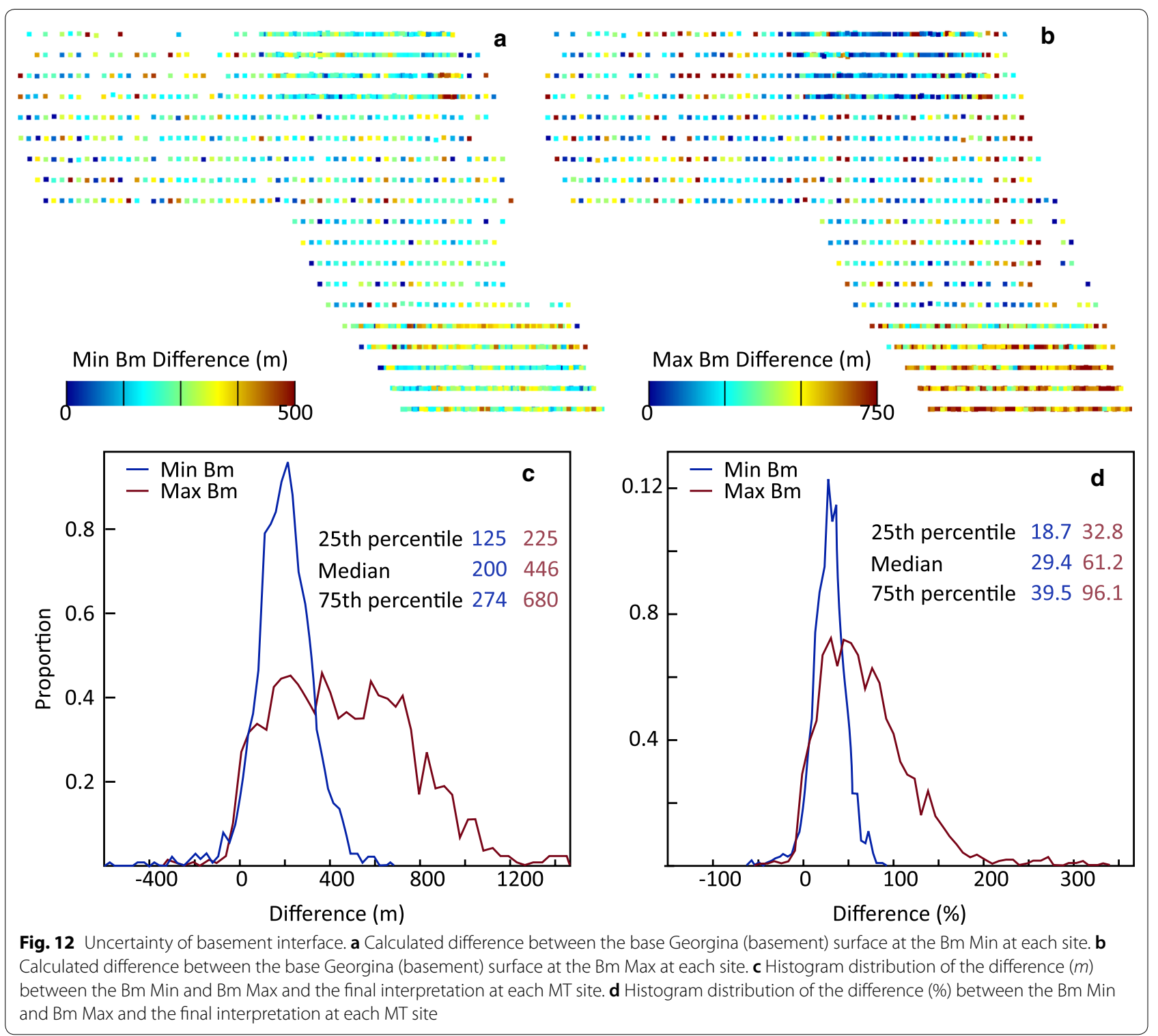

inappropriately applied to $2 \mathrm{D}$ data. The interpretation in these two areas should be treated with additional caution.

The new intra-basin layers provided in our interpretation provide clues that there may be a different between the resistivity structure of the Toko Syncline and Bourke River Structural Belt. A macroscale change in resistivity character for the eastern vs. western parts of the survey was evident in the synthetic modelling. Bradley1 and Todd1 in the west both have a generalised three-layer basin response while Beantree1 has a simple two-layer basin response. The moderate-high resistivity Georgina Basin unit (R1) was not present in Beantree1. This trend also appears in the $2 \mathrm{D}$ inversion results and may represent a difference in sub-basin geology from the Toko
Syncline in the west to the Bourke River Structural Belt in the east. Additional investigation would be required to determine if this is a real trend or simply variability in a small dataset. More broadly, the new interpretation of basin units from this study extends the location of the Georgina Basin sequences further to the south east than previous interpretations (Fig. 1a), suggesting the basin is larger than previously thought.

The new basement interpretation is broadly similar to the Frogtech Geoscience (2018) result (Fig. 13). The Frogtech (2018) interpretation contains more detailed basement geometry, however it fails to accurately predict known basement intersects due to the presence of non-magnetic basement sequences. Our new 


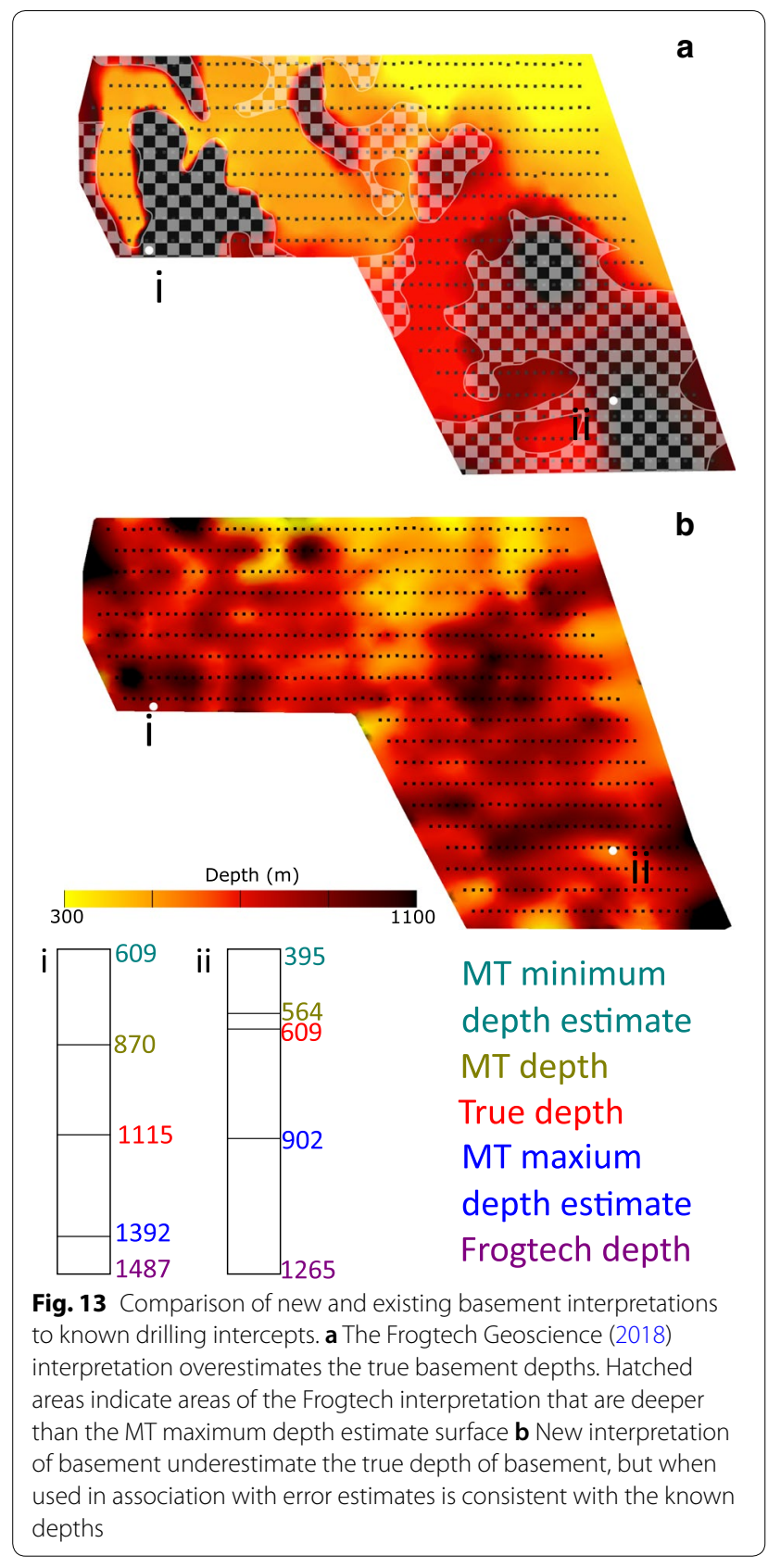

interpretation of basement depth underestimates true basement depth when compared to drilling (Fig. 13b), but if used together with the uncertainty estimates is within error of true depths. It is possible that the interpretation surface underestimates the true basement depth due to the slightly biased nature of the basement interpretation identified in Fig. 11g. Figure 13i and ii shows a comparison of our interpretation's basement depth predictions, the Frogtech (2018) interpretation and the true basement depth from drilling. For both these locations the pre-existing Frogtech (2018) interpretation is deeper than the maximum predicted depth of our new depth to basement interpretation. The hatched areas in Fig. 13a are areas of the Frogtech (2018) interpretation where the maximum interpreted basement depth from our study is shallower than the existing interpretation. These areas are likely to contain non-magnetic basement packages from the Isa or Calvert Superbasins. Validation of our interpretation is based on available drilling, limited to only two holes. Ideally, additional drilling is required to better validate the accuracy of the interpretation.

Two means for estimating interpretation uncertainty were undertaken. Both are objectively derived, rather than being subjectively determined, limiting the influence of interpreter bias. The first method of uncertainty estimation uses the scattering of interpretation picks generated from the 1D inversion results as a proxy inversion uncertainty (Fig. 11). Because the 1D and 2D inversions were parameterised differently and use different inversion methodologies-deterministic vs. probabilistic-the difference in inversion results is likely due to the inherently non-unique nature of inversion modelling. The additional uncertainty estimation for the basement surface was derived from the 1D probabilistic inversion results. Synthetic modelling suggested that the basement interface should be between the Bm Min and Bm Max picks (Fig. 5; see Fig. 6a for selection criteria for Bm Min and $\mathrm{Bm}$ Max). The median distance between the interpreted basement surface and these two picks at each site as a percentage was used as the final estimate of uncertainty. Use of the median value means the uncertainty of the basement surface may be underestimated in some areas, however comparison to the available drilling supports the selected error margins.

There are a number of advantages and limitations associated with the presented approach for characterising basin morphology from MT data. The primary advantage is that the synthetic modelling allows insight gained from a small amount of non-coincident constraining information to be used to better understand inversion results. Use of probabilistic inversion allows an understanding the permissible inversion variability for the dataset in the absence of constraint; while the 2D Occam inversion method produced models that approximate the minimum structure required by the data and enforce a high degree of lateral continuity between MT sites, absent in the $1 \mathrm{D}$ results. Combining multiple inversion methodologies with synthetic modelling is a useful approach in data-poor areas. As MT gains increased acceptance in the mineral exploration industry, more data will be collected in greenfields areas with limited amount of constraining information. 
The presented method allows a large number of inversion results to be integrated into a single, cohesive interpretation. Our study utilises over 2000 1D inversion results and 22 2D inversion profiles. By generating 1D interpretation picks in a software designed to handle drilling logs, and integrating these picks with the $2 \mathrm{D}$ inversion results in a 3D modelling software, we made the task of interpreting such a number of inversion results manageable.

A significant limitation of the presented methodology for using synthetic modelling to inform MT interpretation is that it assumes lateral consistency in resistivity signatures. Extrapolating the results of the current study to the broader Georgina Basin is problematic due to the known presence of thick Neoproterozoic sediments which would be difficult to distinguish from basement. More complex geological settings also present a challenge to the presented method but they do not preclude the use of this method. Complex terranes would require additional synthetic modelling to cover the range of possible geological models in such environments. Practically this work is most applicable to sedimentary basins where lateral continuity of resistivity character and geological units is a reasonable assumption. A sedimentary basin environment, such as the one in this study, allows conclusions from fewer synthetic models to be more broadly applied than would be possible in complex crystalline basement terranes.

\section{Conclusions}

This study demonstrates integration of sparse, non-coincident geological constraint into interpretation of MT inversion results via synthetic modelling. We combine the synthetic modelling with deterministic and probabilistic inversion, to produce three new interpretative geological surfaces in the southern part of the Mount Isa Province, each with an objective estimate of uncertainty.

Downhole resistivity data from petroleum wells were used to generate 1D resistivity models of the Eromanga and Georgina Basins in the study area. Synthetic MT data were generated from the models and used to demonstrate the suitability of various MT inversion algorithms for resolving the expected electrical structure. Basin units could be adequately interpreted from any of the algorithms tested, while the basement interface was poorly constrained. We chose a combination of Occam2D and rj-McMC to provide surety that the 2D data were being adequately modelled and provide uncertainty estimates in interface depths. The new interpretation identifies a potential difference in the petrophysical character of Georgina Basin sediments between the Toko Syncline and Bourke River Structural Belt. A new depth to basement surface was also produced which provides evidence of new extents of non-magnetic basement units associated with either the Isa or Calvert Superbasin.

Combined use of probabilistic inversion and deterministic inversion enabled production of not only an interpretation but also quantified the uncertainty on the interpreted features. The uncertainty varies considerably between interpretation features and is very high on the basement surface. Despite this limitation, valuable new knowledge about the depth to basement and distribution of basement packages was generated in the study area.

This work highlights the importance of understanding inversion variability during interpretation of geological features, particularly in the absence of constraining information. Distribution of uncertainty between the interpretation features is significantly non-uniform, necessitating careful consideration of inversion results. By quantifying uncertainty rather than ignoring it we produce an interpretation commensurate with data limitations that still provides valuable new information about the geology of the southern Mount Isa Province.

\section{Supplementary information}

Supplementary information accompanies this paper at https://doi. org/10.1186/s40623-020-01178-2.

Additional file 1. 1D rj-MCMT inversion record. A record of which 1D rj-McMC inversion result (BBMT, reduced frequency AMT or full frequency AMT) was used for the final interpretation.

Additional file 2. 1D rj-McMT inversion results. Inversion summary figures for all rj-McMT inversions run. Files are grouped by input site type and frequency band: BBMT $\left(10^{1} \mathrm{~Hz}\right.$ to $\left.3 \times 10^{2} \mathrm{~Hz}\right)$, reduced frequency AMT $\left(10^{1} \mathrm{~Hz}\right.$ to $\left.10^{3} \mathrm{~Hz}\right)$ or full frequency AMT $\left(10^{1} \mathrm{~Hz}\right.$ to $\left.10^{4} \mathrm{~Hz}\right)$.

Abbreviations

1D: One dimensional; 2D: Two dimensional; 3D: Three dimensional; AMT: Audiomagnetotelluric; BBMT: Broadband magnetotelluric; MT: Magnetotelluric; rj-McMC: Reverse jump Markov chain Monte Carlo; RF: Reduced frequency; FF: Full frequency; Ero: Base Eromanga basin; GB CT: Georgina Basin conductor top; Bm Min: Basement minimum; Bm CP: Basement change point; Bm Max: Basement maximum; R1: Uppermost moderate/high-resistivity layer; R2: Basement resistivity layer; C1: Low-resistivity surface layer; C2: Low/moderateresistivity layer in the Georgina Basin.

\section{Acknowledgements}

Published with the permission of the Chief Government Geologist of the Geological Survey of Queensland. This work was completed as part of a PhD at the University of Adelaide. The work was conducted with the support of supercomputing resources provided by the Phoenix HPC service at the University of Adelaide. Naser Meqbel is thanked for the use of his 3D Grid software, and Alison Kirkby and Kate Robertson for MTpy support. The authors thank SC Constable and colleagues for the Occam1D and 2D algorithms, R. Brodie et al. for rj-McMC algorithms, and R Cockett et al. for SimPEG algorithms; all of which are made freely available to the academic community. We also thank the Geological Survey of Queensland for access to state geophysical and geological databases. The authors thank Nathan Foks and one anonymous reviewer whose suggestions significantly improved the manuscript. 


\section{Authors' contributions}

Inversion, interpretation and manuscript preparation conducted by JS. GH provided supervision of work and manuscript evaluation. All authors read and approved the final manuscript.

\section{Funding}

This research was funded by Queensland Government, represented by the Department of Natural Resources, Mines and Energy.

\section{Availability of data and materials}

http://qdexdata.dnrme.qld.gov.au/QDEXDataDownloadManager/Resul ts?type=Ground\%20Geophysics\&subtype=\&id=|sa\%20Extension\%20MT.

\section{Ethics approval and consent to participate}

Not applicable.

\section{Consent for publication}

Not applicable.

\section{Competing interests}

Not applicable.

\section{Author details}

${ }^{1}$ Geological Survey of Queensland, Department of Natural Resources, Mines and Energy, Queensland Government, PO Box 15216, City East, QLD 4002, Australia. ${ }^{2}$ Department of Earth Sciences, School of Physical Sciences, University of Adelaide, Adelaide, SA 5005, Australia.

Received: 14 June 2019 Accepted: 15 April 2020

Published online: 14 May 2020

\section{References}

Ambrose GJ, Kruse PD, Putnam PE (2001) Geology and hydrocarbon potential of the southern Georgina Basin, Australia. APPEA J 41:139-163

Barbosa VCF, Silva JBC, Medeiros WE (1997) Gravity inversion of basement relief using approximate equality constraints on depths. Geophysics 62:1745-1757. https://doi.org/10.1190/1.1444275

Bedrosian PA (2007) MT+, Integrating magnetotellurics to determine Earth structure, physical state, and processes. Surv Geophys 28:121-167. https ://doi.org/10.1007/s10712-007-9019-6

Bibby HM, Caldwell TG, Brown C (2005) Determinable and non-determinable parameters of galvanic distortion in magnetotellurics. Geophys J Int 163:915-930. https://doi.org/10.1111/j.1365-246X.2005.02779.x

Brodie R, Jiang W (2018) Trans-dimensional Monte Carlo inversion of short period magnetotelluric data for cover thickness estimation. Australian Exploration Geoscience Conference, Sydney

Cai H, Zhdanov MS (2015) Magnetotelluric inversion for depth-to-basement estimation, SEG New Orleans Annual Meeting, pp 874-878

Cai H, Zhdanov MS (2017) Joint inversion of gravity and magnetotelluric data for the depth-to-basement estimation. IEEE Geosci Remote Sens Lett 14:1228-1232. https://doi.org/10.1109/LGRS.2017.2703845

Caldwell TG, Bibby HM, Brown C (2004) The magnetotelluric phase tensor. Geophys J Int 158:457-469. https://doi.org/10.1111/j.1365246X.2004.02281.x

Carreira VR, La Terra EF, Fontes SL (2018) Density model for the central part of Parana Basin, using magnetotellurics as basement constraint, southern portion of Brazil. Revista Brasileira de Geofísica 36:59. https://doi. org/10.22564/rbgf.v36i1.893

Cockett R, Kang S, Heagy LJ et al (2015) SimPEG: an open source framework for simulation and gradient based parameter estimation in geophysical applications. Comput Geosci 85:142-154. https://doi.org/10.1016/j.cageo .2015 .09 .015

Constable SC, Parker RL, Constable CG (1987) Occam's inversion: a practical algorithm for generating smooth models from electromagnetic sounding data. Geophysics 52:289-300. https://doi.org/10.1190/1.1442303

Cook AG, Bryan SE, Draper JJ et al (2013) Post-orogenic Mesozoic basins and magmatism. In: Jell PA (ed) Geology of Queensland. City East, Queensland Government, pp 515-576
deGroot-Hedlin C, Constable S (1990) Occam's inversion to generate smooth, two-dimensional models from magnetotelluric data. Geophysics 55:1613-1624. https://doi.org/10.1190/1.1442813

Draper J (2007) Georgina Basin—an early Palaeozoic carbonate petroleum system in Queensland. APPEA J 47:105-124

Egbert GD, Kelbert A (2012) Computational recipes for electromagnetic inverse problems. Geophys J Int 189:251-267. https://doi.org/10.1111/ j.1365-246X.2011.05347.x

Evans RL (2012) Conductivity of Earth materials. In: Chave AD, Jones AG (eds) The magnetotelluric method theory and practice. Cambridge University Press, Cambridge, pp 50-95

Frogtech Geoscience (2018) North West Queensland SEEBASE ${ }^{\circledR}$ Study and GIS Queensland Geological Record 2018/3 Brisbane Australia. https://qdexg uest.dnrm.qld.gov.au/portal/site/qdex/

Gallardo-Delgado LA, Pérez-Flores MA, Gómez-Treviño E (2003) A versatile algorithm for joint 3D inversion of gravity and magnetic data. Geophysics 68:949-959. https://doi.org/10.1190/1.1581067

Garcia X, Jones AG (2008) Robust processing of magnetotelluric data in the AMT dead band using the continuous wavelet transform. Geophysics 73:F223-F234. https://doi.org/10.1190/1.2987375

Gibson GM, Meixner AJ, Withnall IW, Korsch RJ, Hutton LJ, Jones LEA, Holzschuh J, Costelloe RD, Henson PA, Saygin E (2016) Basin architecture and evolution in the Mount Isa Mineral Province, Northern Australia: constraints from deep seismic reflection profiling and implications for ore genesis. Ore Geol Rev 76:414-441. https://doi.org/10.1016/j.orege orev.2015.07.013

Green DC, Hamling DD, Kyranis N (1963) CR1065: A-P 54P, PPC Elizabeth Springs 1, PPC Beantree 1, PPC Canary 1, PPC Black Mountain 1, stratigraphic drilling, Boulia area, well completion report. https://qdexguest. dnrm.qld.gov.au/portal/site/qdex/

Greene DC (2010) Neoproterozoic rifting in the southern Georgina Basin, central Australia: implications for reconstructing Australia in Rodinia. Tectonics 29:20. https://doi.org/10.1029/2009tc002543

GSQ (2011) North-west Queensland mineral and energy province report. Geological Survey of Queensland, Brisbane

Kelbert A, Meqbel N, Egbert GD, Tandon K (2014) ModEM: a modular system for inversion of electromagnetic geophysical data. Comput Geosci 66:40-53. https://doi.org/10.1016/j.cageo.2014.01.010

Kress AG (1989) CR20150: PGA Bradley NO. 1, A-P 380P, well completion report. https://qdexguest.dnrm.qld.gov.au/portal/site/qdex/

Kress AG, Simeone SF (1993) CR24824: A-P 380P, PGA Todd 1, well completion report. https://qdexquest.dnrm.qld.gov.au/portal/site/qdex/

Krieger L, Peacock JR (2014) MTpy: a Python toolbox for magnetotellurics. Comput Geosci 72:167-175. https://doi.org/10.1016/j.cageo.2014.07.013

Kruse PD, Dunster JN, Munson TJ (2013) Georgina Basin. In: Ahmad M, Munson TJ (eds) Geology and mineral resources of the Northern Territory. Northern Territory Government Printing Office, Darwin, p 28

Le CVA, Harris BD, Pethick AM et al (2016) Semiautomatic and automatic cooperative inversion of seismic and magnetotelluric data. Surv Geophys 37:845-896. https://doi.org/10.1007/s10712-016-9377-z

Majcin D, Bezák V, Klanica R et al (2018) Klippen Belt, Flysch Belt and inner western Carpathian Paleogene Basin relations in the northern Slovakia by magnetotelluric imaging. Pure Appl Geophys 175:3555-3568. https://doi. org/10.1007/s00024-018-1891-0

Moorkamp M, Roberts AW, Jegen M et al (2013) Verification of velocity-resistivity relationships derived from structural joint inversion with borehole data. Geophys Res Lett 40:3596-3601. https://doi.org/10.1002/grl.50696

Moreau F, Gibert D, Holschneider M, Saracco G (1999) Identification of sources of potential fields with the continuous wavelet transform: basic theory. J Geophys Res 104:5003-5013. https://doi.org/10.1029/1998JB900106

Naudy H (1971) Automatic determination of depth on aeromagnetic profiles. Geophysics 36:717-722. https://doi.org/10.1190/1.1440207

Ogawa Y (2002) On two-dimensional modelling of magnetotelluric field data. Surv Geophys 23:251-273. https://doi.org/10.1023/A:1015021006018

Ogaya X, Alcalde J, Marzán I et al (2016) Joint interpretation of magnetotelluric, seismic, and well-log data in Hontomín (Spain). Solid Earth 7:943-958. https://doi.org/10.5194/se-7-943-2016

Parker RL (1994) Geophysical inverse theory. Princeton University Press, Princeton 
Reid AB, Allsop JM, Granser H et al (1990) Magnetic interpretation in three dimensions using Euler deconvolution. Geophysics 55:80-91. https://doi. org/10.1190/1.1442774

Roach IC, Folkes CB, Goodwin J et al (2018) Applied geophysics for cover thickness mapping in the southern Thomson Orogen. Aust J Earth Sci. https:// doi.org/10.1080/08120099.2018.1452295

Selway K (2014) On the causes of electrical conductivity anomalies in tectonically stable lithosphere. Surv Geophys 35:219-257. https://doi. org/10.1007/s10712-013-9235-1

Simpson F, Bahr K (2005) Practical magnetotellurics. Cambridge University Press, Cambridge

Thiel S (2008) Modelling and inversion of magnetotelluric data for 2-D and 3-D lithospheric structure, with application to obducted and subducted terranes. Ph.D. dissertation, The University of Adelaide

Thurston JB, Smith RS (1997) Automatic conversion of magnetic data to depth, dip, and susceptibility contrast using the SPI (TM) method. Geophysics 62:807-813. https://doi.org/10.1190/1.1444190

Walter MR, Veevers JJ, Calver CR, Grey K (1995) Neoproterozoic stratigraphy of the Centralian Superbasin, Australia. Precambr Res 73:173-195. https:// doi.org/10.1016/0301-9268(94)00077-5

Weaver JT, Lilley FEM (2004) Using Mohr circles to identify regional dimensionality and strike angle from distorted magnetotelluric data. Explor Geophys 35:251. https://doi.org/10.1071/EG04251
Weaver JT, Agarwal AK, Lilley FEM (2000) Characterization of the magnetotelluric tensor in terms of its invariants. Geophys J Int 141:321-336. https:// doi.org/10.1046/j.1365-246x.2000.00089.x

Werner S (1953) Interpretation of magnetic anomalies of sheet-like bodies. Sveriges Geologiska Undersökning 43:1-130

Withnall IW, Hutton LJ, Armit RJ et al (2013) North Australian Craton. In: Jell PA (ed) Geology of Queensland. City East, Queensland Government, pp 23-112

Yan P (2016) Inversion of magnetotelluric data constrained by borehole logs and reflection seismic sections. Ph.D. dissertation Universitatis Upsaliensis

Yan P, Kalscheuer T, Hedin P, Garcia Juanatey MA (2017) Two-dimensional magnetotelluric inversion using reflection seismic data as constraints and application in the COSC project. Geophys Res Lett 44:3554-3563. https:// doi.org/10.1002/2017GL072953

Zevallos I, Assumpção M, Padilha AL (2009) Inversion of teleseismic receiver function and magnetotelluric sounding to determine basement depth in the Paraná Basin, SE Brazil. J Appl Geophys 68:231-242. https://doi. org/10.1016/j.jappgeo.2008.11.002

\section{Publisher's Note}

Springer Nature remains neutral with regard to jurisdictional claims in published maps and institutional affiliations.

\section{Submit your manuscript to a SpringerOpen ${ }^{\circ}$ journal and benefit from:}

- Convenient online submission

- Rigorous peer review

- Open access: articles freely available online

- High visibility within the field

- Retaining the copyright to your article

Submit your next manuscript at springeropen.com 